\title{
LA MAQBARA DEL CAMINO DE BAYYĀSA (MARROQUÍES BAJOS, JAÉN)
}

\author{
THE MAQBARA OF THE BAYYĀSA PATH (MARROQUÍES BAJOS, JAÉN)
}

\author{
MERCEDES NAVARRO PÉREZ \\ Universidad de Jaén \\ mnperez@ujaen.es \\ https://orcid.org/0000-0001-6440-6737
}

Recepción: 20-03-2018

Aceptación: 02-07-2018

\section{Resumen}

En el texto se presenta un estudio realizado sobre las necrópolis medievales documentadas en la Zona Arqueológica de Marroquíes Bajos, (Jaén) y especialmente de la maqbara del camino de Bayyāsa. Para ello se exponen las diferentes variables, tipología de tumba, localización dentro del propio cementerio, orientación, etc, que nos han permitido plantear hipótesis sobre su fundación en época emiral y su evolución durante todo el período islámico, incluidos algunos períodos en los que se produce el abandono del mismo coincidiendo con momentos de inestabilidad.

Palabras clave. Marroquíes Bajos; al-Andalus; maqbara; camino; tipología de enterramientos.

\begin{abstract}
The text presents a study on the medieval necropolises documented in the archaeological area of Marroquíes Bajos (Jaén) and, especially, the maqbara of the Bayyāsa road. In order to do so, we expose the different variables, typology of the tomb, location within the cemetery itself, orientation, etc. Thich has allowed us to formulate hypotheses about its foundation in the emiral period and its evolution throughout the Islamic period, including some instability moments in which it is abandoned.
\end{abstract}

Key words. Marroquíes Bajos; al-Andalus; maqbara; path; burial typology. 


\section{INTRODUCCIÓN}

Desde 1995 se viene excavando con metodología arqueológica una gran extensión de terreno situado en el extremo norte de la ciudad de Jaén y que, entre otros elementos, proporciona un amplio conjunto de estructuras de diverso tipo fechadas entre los siglos IX y XII. El análisis y caracterización de éstas, y las inmediatamente anteriores, tanto individualmente como en conjunto, permiten introducirnos en la evolución histórica y arqueológica de la zona en época islámica.

Este gran espacio denominado Marroquíes Bajos (Fig.1), hasta finales del siglo XX, fue una amplia área de huertas con más de 500 ha, que se había mantenido como tal, gracias a la presencia de la estación del tren y las vías ferroviarias que suponían un límite de contención de la expansión de la ciudad hacia el norte (Hornos Mata et al., 1998). Una vez que la estación de ferrocarril se desplaza hacia el oeste, la zona se convierte en el área de expansión por excelencia de la ciudad. Con el inicio de las obras de urbanización comenzaron a salir a la luz los primeros restos arqueológicos, que abarcan una cronología que se extiende desde el tercer milenio a.C. hasta la actualidad (Zafra de la Torre et al., 1999; Sánchez Vizcaíno et al., 2005).
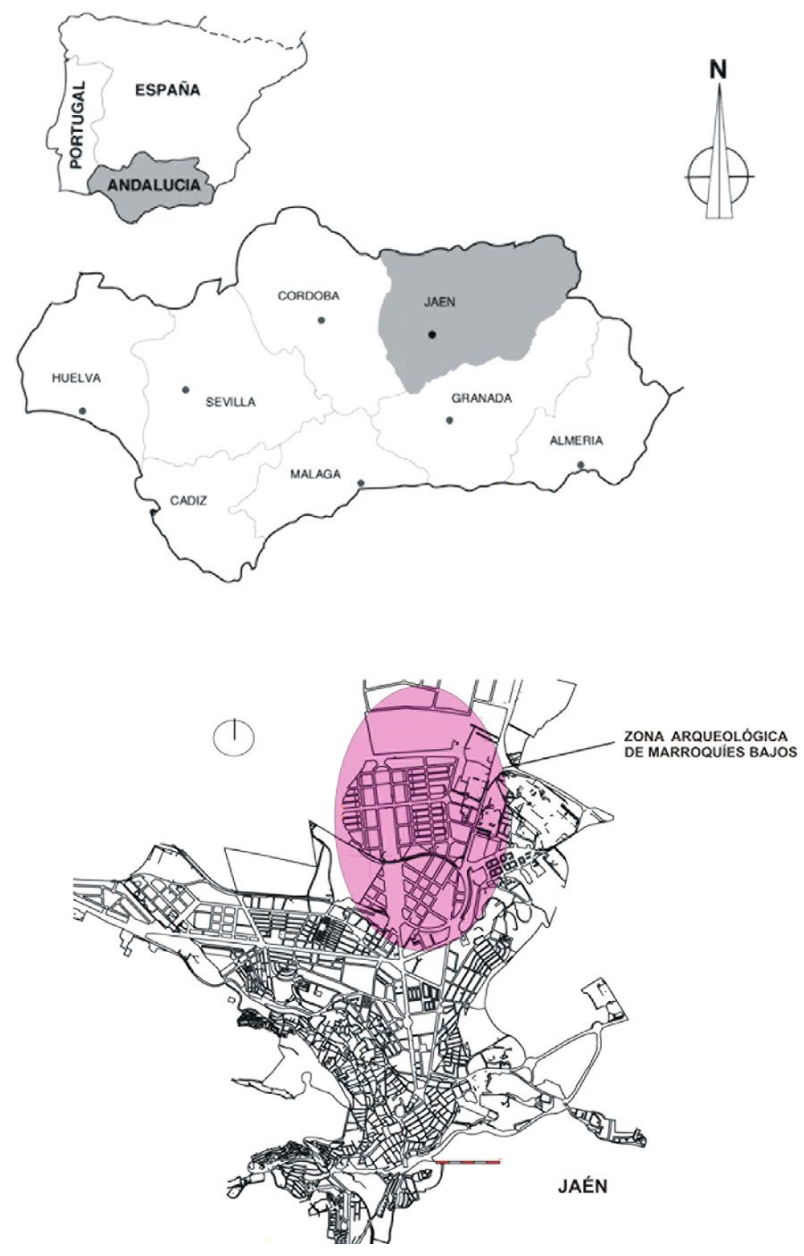

Figura 1: Situación.
Desde las primeras fases de ocupación, Marroquíes Bajos sufrió una gran transformación del paisaje, documentada en época calcolítica, con la apropiación de diferentes arroyos que son encauzados y dirigidos hacia varios fosos concéntricos que sirven, a su vez, de defensa y de abastecimiento. Estas construcciones son abandonadas progresivamente, y terminan colmatándose dejando su impronta, especialmente el cuarto foso, que se encontraba defendido por una gran muralla de adobes. Estas huellas marcarán las siguientes ocupaciones del terreno (Castro López et al., 2008; Navarro Pérez, 2015), incluidas las de época islámica (Navarro Pérez, 2017).

Las noticias sobre hallazgos o excavaciones arqueológicas de época islámica en la ciudad de Jaén y sus alrededores eran prácticamente inexistentes hasta los años 90 del siglo XX. No se podían identificar ningunas de las maqābir que debían existir tanto en el entorno más inmediato de la ciudad como en los alrededores y, menos aún, epígrafes funerarios, epitafios que nos permitan identificar tumbas de individuos concretos, como en las halladas en necrópolis de Córdoba, Orihuela (Alicante) o Almería (Martínez Núñez, 2011).

En cuanto a las fuentes escritas nos enfrentamos a un gran vacío documental, que afecta del mismo modo a las necrópolis tardoantiguas, a las visigodas, judías y a las musulmanas. Sólo tenemos una noticia recogida en las crónicas de la conquista por las tropas de Fernando III, en la que se cita en varias ocasiones el Fonsario o Puerta del Fonsario (Aguirre Sádaba y Jiménez Mata, 1979; Lázaro Damas, 1998; Serrano Peña y Castillo Armenteros, 2000). Sobre la localización de este espacio no hay consenso, las fuentes no son muy claras a la hora de su descripción. J. Eslava Galán (1999) indica que podría tratarse de un paraje denominado $L a$ Vega que se encontraría entre las puertas de Martos, el Aceituno y la puerta Baeza. Por otro lado, S. Lázaro, localizó unas escrituras del año 1630 sobre unas huertas de la zona en torno a la Puerta de Martos donde se menciona un cementerio (Barba Colmenero et al., 2004).

En los últimos años se han realizado excavaciones en las que se han documentado enterramientos que podrían formar parte de los cementerios situados junto a las antiguas puertas de la ciudad (Fig.2), como es el caso de la Puerta de Martos (Barba Colmenero et al., 2004), la Puerta del Aceituno (Pérez Martínez et al., 2004) o la Puerta de Granada. De esta última no conocemos su situación exacta, pero muy cerca de la que tuvo que ser su localización, en un solar situado en la calle del Conde, se han excavado restos de lo que fue uno de los cementerios islámicos de la ciudad almohade, con un total de 65 inhumaciones (Martínez Ocaña y Manzano Castillo, 2010). Otra de las necrópolis con ritual islámico documentada en la actual ciudad de Jaén es la realizada en la Plaza de la Constitución, en ella se documentó un arrabal de época islámica dedicado a la alfarería. Una vez abandonadas estas estructuras, según sus autores, ya durante el asedio de las tropas cristianas se utiliza como cementerio (Manzano Castillo y 


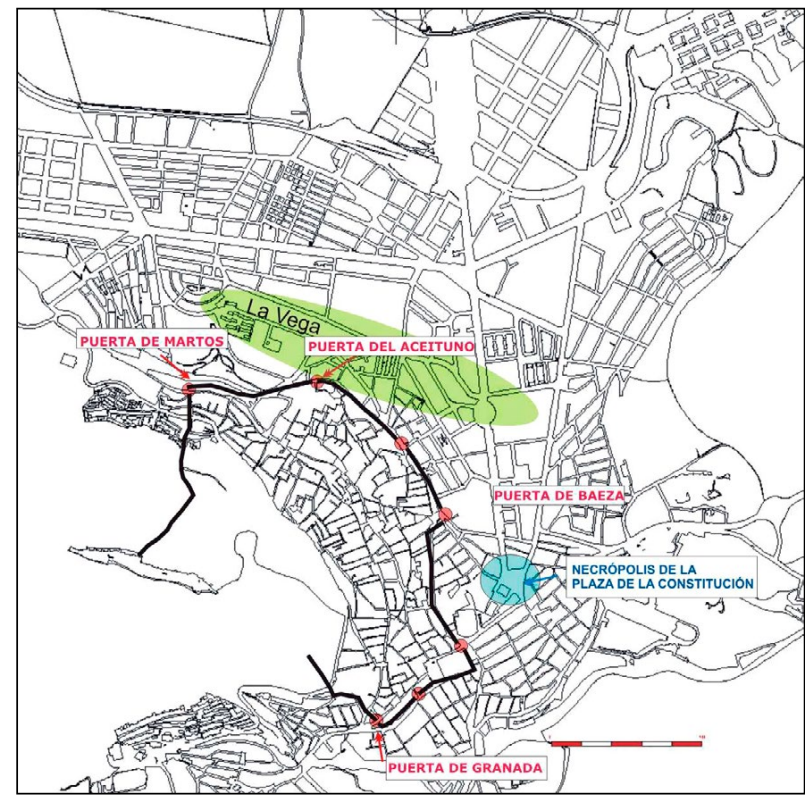

Figura 2: Localización de las Puertas más importantes de la ciudad de Jaén.

Martínez Ocaña, 2009). V. Salvatierra (2009), indica que este cementerio debió de fundarse con anterioridad al asedio, poco antes de la conquista castellana.

La mayoría de los estudios centrados en necrópolis de al-Andalus se dedican al mundo urbano, los trabajos sobre necrópolis rurales son escasos, y los que hay se refieren a la antigüedad tardía, visigodos o a períodos islámicos tardíos la mayoría almohades o nazaríes, mientras que apenas contamos con ejemplos de maqābir de época omeya.

El motivo de esta desigualdad a la hora de documentar necrópolis en el ámbito urbano y en el rural, tiene una doble vertiente. Por un lado, las propias actuaciones arqueológicas que se han desarrollado más en el interior de las ciudades y, sobre todo, en los círculos más cercanos a ellas debido al crecimiento que estas experimentaron a finales del siglo XX. Por el contrario, en las pequeñas localidades y en el campo apenas han tenido incidencia, en algunas porque no se ha producido un crecimiento similar al de las grandes ciudades, pero sobre todo, porque no se ha realizado un seguimiento y control arqueológico. La mayoría de estas localidades no tienen una zonificación arqueológica dentro de sus planes urbanísticos que las proteja. Por otro lado, tampoco hay una concienciación sobre el patrimonio arqueológico, entendiéndolo como parte de su propia entidad y su cultura. Por tanto, en muchas ocasiones los hallazgos que se producen en estas son silenciados, ocultados o destruidos.

En los últimos años, finales del siglo XX principios del XXI, las grandes infraestructuras realizadas para la construcción de carreteras y otras obras que abarcaban amplias áreas de intervención, han sacado a la luz algunas zonas de ocupación y enterramiento de espacios rurales. Estos trabajos han permitido superar, en algunas ocasiones, la problemática que se planteaba hasta ese momento, en que la mayoría de las necrópolis no tienen documentada su correspondiente población. No obstante, como señala Vigil-Escalera, (2013: 268) no siempre es así, de hecho, este mismo autor indica que de los once yacimientos que se estudian en el volumen, El poblamiento rural de época Visigoda en Hispania sólo seis «proporcionan evidencias acerca de la relación existente entre el espacio funerario y áreas residenciales y productivas». El caso de Marroquíes Bajos, lo tendríamos que encuadrar dentro de estos yacimientos, que como hemos visto, se documentan gracias al crecimiento de la ciudad de Jaén.

\section{ESPACIOS FUNERARIOS Y RELIGIOSOS. LA HUELLA DE LAS NECRÓPOLIS MEDIEVALES EN LA ZONA ARQUEOLÓGICA DE MARRO- QUÍES BAJOS (ZAMB)}

En los primeros años de las investigaciones realizadas en la Zona Arqueológica se identificaron hasta siete necrópolis medievales, cuatro de ellas de rito cristiano, dos de rito islámico y una mixta (Serrano Peña y Castillo Armenteros, 2000). Actualmente han salido a la luz nuevos restos por lo que hemos hecho una revisión de los datos divulgados hasta el momento, aplicando nuevos estudios cuyos resultados matizan en parte lo publicado en el año 2000 y posteriormente en el año 2011 (Castillo Armenteros et al., 2011).

La elección de la localización para ubicar una necrópolis no es algo que se haga al azar. Las necrópolis medievales, tanto de rito cristiano como islámico documentadas en Marroquíes Bajos, las podemos dividir en varias clases según su localización:

1.- Necrópolis en torno a caminos. La importancia de las vías de comunicación a la hora de situar los cementerios es primordial. La Zona Arqueológica de Marroquíes Bajos (ZAMB) se encuentra vinculada a varios caminos de gran importancia en la antigüedad y a otros menores, pero todos ellos partían de la Puerta de Baeza o Bayyāsa, una de las más importantes de la ciudad de Jaén. Hace unos años pudimos excavarla como consecuencia de la remodelación de la Plaza de los Huérfanos donde se encontraba. La puerta data de época almohade, por lo que podemos deducir que este camino ya existía en época islámica, aunque no descartamos que se asentara sobre otro de época romana. Esta vía, que hoy no existe, ha sido documentada a nivel arqueológico en las diferentes excavaciones realizadas en la ZAMB (Vial 5-5, tramo 1 y C/B-B', Tramo 5; Parcela 55, Centro de Salud del RP-44 y Plaza de Jaén por la Paz). Una de ellas es la Intervención Arqueológica en el Solar de la Futura Ciudad de la Justicia, en la cual, aunque en un primer momento se identificó (Navarro Pérez, 2008; 2009) como una zona de respeto entre las viviendas localizadas al lado oeste y la maqbara situada en el límite este, posteriormente, cuando realizamos la superposición de la cartografía 
antigua y las intervenciones arqueológicas realizadas, comprendimos que se correspondía con parte del antiguo camino (Navarro Pérez, 2015).

2.- Necrópolis relacionadas con los cursos de agua. En ocasiones las necrópolis, y especialmente las islámicas, estaban delimitadas por arroyos. Como ejemplo de este tipo de relaciones, diversos autores (León Muñoz y Casal García, 2010) proponen la necrópolis islámica de Marroquíes Bajos, a la que van dedicadas estas líneas. El agua está íntimamente relacionada con las creencias escatológicas del mundo musulmán (León Muñoz y Casal García, 2010), especialmente con los trances que debía de pasar el difunto durante el tiempo que éste se encontraba en la tumba. Tras el interrogatorio al que era sometida el alma por los dos ángeles de la tumba, Munkar y Nakīr, el cuerpo de los pecadores era expuesto, entre otros, a un insoportable calor (Fierro Bello, 2000), por lo que el agua se consideraba como una fuente de purificación y de alivio durante el tiempo que éste estaba en la sepultura. De hecho, M. Fierro (2000: 182), indica que esta era «la razón por la cual era necesario refrescarlas (las tumbas) plantando vegetación o vertiendo agua.» En las primeras propuestas sobre la fundación y delimitación de la necrópolis islámica de Marroquíes Bajos se manejaron, como factores decisivos, la ubicación junto a arroyos y canales. Con las nuevas investigaciones realizadas, estas primeras hipótesis tienen que ser, de nuevo, matizadas, si la relación entre las necrópolis y los caminos es evidente a simple vista, cuando se superpone la planimetría de los caminos y la de las áreas funerarias, no sucede igual con el plano de arroyos y necrópolis.

3.- Necrópolis en torno a edificios religiosos. Durante la tardoantiguedad y el período visigodo, los cementerios surgen en torno a un espacio sagrado, iglesias o estructuras conventuales, extendiéndose tanto en el interior como el exterior del edificio, aunque nunca o casi nunca ocupando el área del ábside donde se oficiaba. Esta característica se mantiene, esencialmente, con la sociedad hispanorromana (Ripoll López, 1989) y será a partir del Concilio de Braga en el año 561, cuando no se pueda enterrar en el interior de los edificios religiosos (López Quiroga y Martínez Tejera, 2009). Aunque el arraigo de estas costumbres era tal, que en muchos casos no se cumplió, algo que, como han reseñado López y Martínez (2009), ha sido constatado ampliamente por la arqueología.

En época visigoda y primeros momentos tras la conquista, se observa en el territorio que ocupa la ZAMB, una nueva organización del espacio. Los campos estarían ocupados por la propia población indígena, no obstante, la Iglesia tendría un papel muy importante con el establecimiento de edificios religiosos desde donde se controlaban la propiedad y la producción del cultivo extensivo de productos de secano como el cereal (Salvatierra Cuenca, 2010). Dos de estos probables edificios se encontrarían dentro de los límites de Marroquíes Bajos. Por un lado, en el extremo norte del yacimiento, donde en época bajoimperial se ubicaba un complejo industrial de producción de aceite de oliva, y donde posteriormente se construye una basílica cristiana (Serrano Peña y Molinos Molinos, 2011; Navarro Pérez, 2015; Portero Fernández et al., 2010). Este edificio parece estar vinculado a una necrópolis que perdura desde el siglo II hasta el siglo VII (Serrano Peña y Molinos Molinos, 2011). En el otro extremo, al sur, en la Parcela D del RP-4, se documentó parte de una construcción de cierta entidad que se interpreta como un edificio religioso (Castillo Armenteros et $a l$., 2011; Navarro Pérez, 2015). Este está íntimamente relacionado con varias necrópolis. En ambos casos, los edificios debieron de ser desmantelados en época islámica, ya que parte de sus elementos constructivos se utilizan para la edificación de nuevas estructuras calificadas como andalusíes (Salvatierra Cuenca et al., 1998; Serrano Peña et al., 2002; Serrano Peña y Salvatierra Cuenca, 2012).

Maqābir en torno a una mezquita o una musalla. Según un hadīt atribuido al Profeta debía de haber una separación clara entre los lugares de enterramiento y los de oración, y nunca estarían asociados (Fierro Bello, 2000). Basándose en las tradiciones y comentarios de Ibn Hazm de Córdoba, Calvo Capilla (2004) llega a la conclusión de que no había problema si la sepultura se realizaba en un edificio ya construido salvo que fuera una mezquita. No obstante, y según esta misma autora, en todo el mundo islámico surgieron mezquitas asociadas directamente a una tumba, las primeras se levantaron sobre los enterramientos de los mártires originados durante las conquistas musulmanas de oriente en los siglos VII y VIII. La cercanía de mezquitas u oratorios y cementerios es habitual, aunque los edificios no estaban destinados a recoger reliquias ni a ejecutar parte del ritual funerario.

\section{LA MAQBARA DEL CAMINO DE BAYYĀSA}

La denominada gran maqbara, por ser el cementerio islámico de mayor tamaño documentado en la actual ciudad de Jaén, se localiza en el extremo noreste del RP-4 y en parte de la de UA-23, aunque en esta última sólo residualmente, ya que se han documentado cuatro tumbas en el límite oeste de manzana E. La necrópolis en época andalusí se caracterizaba por estar delimitada por el propio camino de Bayyāsa (Fig. 3) que ponía término a su expansión hacia el oeste y a la vez se convierte en un factor esencial en la vertebración y evolución de la necrópolis. Mientras, hacia el sur y el este la maqbara es un espacio abierto propicio para su propia expansión. Para finalizar la descripción de los límites de la maqbara, nos situaremos en el norte, donde la existencia de un barranco, aunque en parte colmatado, parece que funcionó como límite de ésta. No obstante, la delimitación de la necrópolis dependerá de la fase histórica y de la evolución de la misma. 


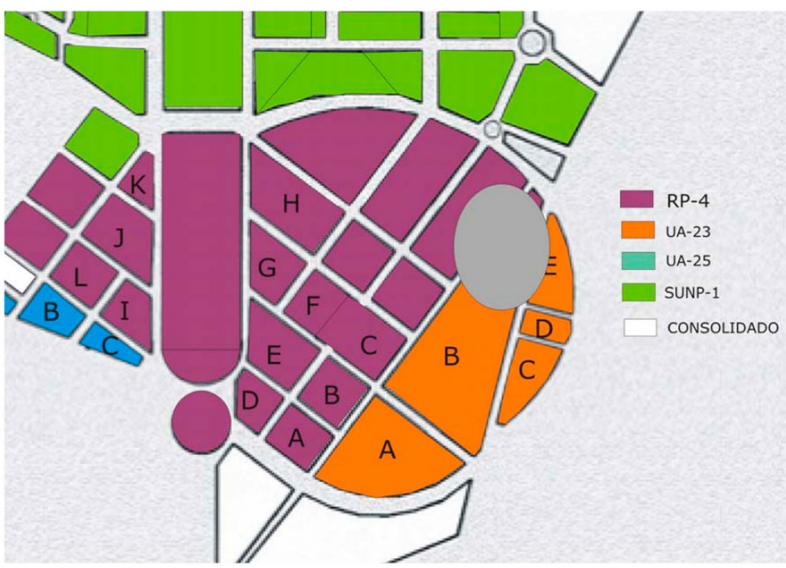

Figura 3: Localización de la maqbara de Bayyāsa.

\subsection{ORGANIZACIÓN INTERNA DE LA MAQBARA}

En un principio, tras la excavación de la parcela de la futura Ciudad de la Justicia, se identificaron tres elementos claramente diferenciados como parte de la necrópolis: tapia, área de respeto y, finalmente, el área de enterramiento propiamente dicha (Barba Colmenero y Navarro Pérez, 2010; Castillo Armenteros et al., 2011).

- Tapia de delimitación de una gran propiedad colindante con el cementerio. Recorre la parcela de la Ciudad de la Justicia de norte a sur y está construida por muros de tapial que se apoyan sobre un zócalo de mampostería irregular (Castillo Armenteros et al., 2011). En realidad, esta tapia no forma parte de la necrópolis, aunque se contempla como un elemento más del paisaje que la rodea, conformando una imagen que perdura durante todo el período omeya.

- Área de respeto. Este espacio, como en el caso anterior, en las primeras investigaciones se interpretó como una zona no ocupada entre el cementerio y las viviendas. En realidad, se trata del camino de Bayyāsa a su paso por la maqbara, discurriendo de forma paralela y contigua al muro o tapia anterior. Este camino, al pasar junto al cementerio, tiene una anchura media de 8,5 $\mathrm{m}$ y se asienta directamente sobre la base geológica, no conservándose restos de ningún tipo de pavimento.

- Área de enterramientos propiamente dicha, en la que se han documentado en torno a 652 enterramientos hasta el momento, distribuidos en un área de $2.135 \mathrm{~m}^{2}$. Cuando aludimos a esta necrópolis, nos referimos a un amplio espacio que ha estado funcionando con este fin durante varios siglos, pero no siempre con la misma intensidad, ni ocupó la misma amplitud espacial. Por tanto, estas cifras no nos aportan una realidad cronológica, sólo son datos que hay que interpretar, en ningún momento la necrópolis ocupó toda el área, ni se pudieron apreciar 652 tumbas alineadas unas junto a otras. La maqbara contaba con sepulturas distribuidas por todo el espacio, todas ellas excavadas en la base geológica o en la tierra, sin que sobresalieran estructuras construidas en alzado, a excepción de una identificada como mausoleo, turba, rawda o qubba.

«Sabido es que el propio profeta recomendaba practicar los enterramientos a ras de suelo y condenaba que se convirtieran en lugares de culto o se elevaran monumentos funerarios sobre ellos» (Abad Castro y Gonzáles Cabero, 2008: 7; Ribera y Tarragó, 1928). Tampoco se podía cubrir la sepulturas con yeso o escribir sobre ellas (Yusuf Raghib, 1970, 1992), todo ello para que los enterramientos no reflejaran el estatus social o la fortuna del individuo enterrado. Esto será asumido por todas las escuelas jurídicas incluida la mālikí que era la predominante en al-Andalus. (Martínez Núñez,1994). En realidad se convierte en una prohibición para evitar que estas tumbas sean lugares de peregrinación (Chávet Lozoya, 2015), y que se produzca el culto a los muertos o la idolatría (Bianquis Thierry, 1994). A pesar de ello, desde el principio del Islam, se fueron edificando estructuras sobre algunas tumbas, incluso a partir del siglo IX se generaliza sobre todo en los enterramientos de las dinastías gobernantes (Abad Castro y Gonzáles Cabero, 2008). De hecho, como señalan diversos autores (Casal García, 2003: 294; Castillo Armenteros et al., 2011: 284; Torres Balbas, 1957: 151), parece que era frecuente que alojaran los «restos de letrados, ascetas, taumaturgos o varones señalados por su santidad y vida piadosa, en tomo a los cuales se enterraban las gentes para beneficiarse de la influencia espiritual que de ellos irradiaba» (Casal García, 2003: 294). Para M. Fierro (2000), la prohibición de la construcción de este tipo de estructuras no se aplicaba en los cementerios privados o, al menos, no de igual manera que en los de uso comunitario. ¿Podría explicar esto la presencia de este elemento en la necrópolis? Esto implicaría que la maqbara inicialmente sería de origen privado o que los individuos enterrados tendrían un carácter de santidad reconocido por la comunidad de Marroquíes Bajos asentada en el entorno del camino de Bayyāsa. Los santones tenían un «foco de gracia que mantenían después de su muerte» (Casal García, 2005: 308) y que se denomina baraka, lo que hacia que la población deseara enterrarse junto a ellos. No obstante, M. ${ }^{\mathrm{a}}$ A. Martínez Núñez 2011: 182) indica que «la austeridad prescrita por los alfaquies en esta materia, relacionada con otras controversias doctrinales sobre "el culto a los santos" y la "veneración de las tumbas", nunca fue respetada, salvo en casos muy puntuales y en sectores de población carentes de recursos económicos, llegando a producirse una disociación muy acusada entre teoría jurídica y práctica social, tal vez porque la ornamentación de las tumbas era considerada por algunos fuqahā como un hecho reprobable (makrūh), no prohibido (haram) de forma tajante».

Este «mausoleo» se encuentra localizado en el extremo noroeste de la necrópolis, junto al limite oriental del camino y enfrentado a la denominada vivienda 
n. ${ }^{\text { }} 1$ del futuro solar de la Ciudad de la Justicia. Esta vivienda conforma un amplio espacio residencial y de producción, colindante con el cementerio, siendo la que muestra la cronología más temprana de las documentadas en el entorno. A finales del siglo IX sufre un repentino abandono (Navarro Pérez, 2009; Barba Colmenero y Navarro Pérez, 2010; Castillo Armenteros et al., 2011; Navarro Pérez, 2015), que suponemos que está íntimamente relacionado con los enfrentamientos de algunos jefes muladíes en el territorio de Ŷayyān durante los años 889 a 913 (Salvatierra Cuenca, 2001). La estructura funeraria documentada tiene forma rectangular, abierta en su lado oriental, aunque cabe la posibilidad de que el cerramiento no se haya conservado, ya que no se ha documentado un remate en ninguno de sus lados que nos indique la posibilidad de una terminación. No obstante, podría indicar la presencia de un pequeño vano de acceso. No parece presentar un aspecto monumental, aunque es verdad que sólo contamos con su cimentación, ya que esta estructura se encuentra muy arrasada, pero los materiales de construcción y sus dimensiones, 3 x 2,30 m, así nos lo sugiere.

El mausoleo abarca dos tumbas, ambas encuadradas dentro de la tipología de prefosa y fosa de inhumación, pero con diferencias importantes entre ellas. El primer enterramiento que se realiza presenta el tipo lahd o cámara lateral, con tendencia a la covacha que se localizaba en la zona sureste de la tumba. En su interior se encontraba el cadáver de un varón adulto (Barba Colmenero y Navarro Pérez, 2010) en posición de decúbito lateral derecho. Esta fosa de inhumación, orientada a $200^{\circ}$, con tendencia hacia el este, estaría cubierta probablemente por una tabla de madera compuesta por varias piezas, ya que en el interior de la tumba se documentó un clavo de hierro. Originalmente este enterramiento estaba tapado por un pequeño túmulo de tierra que sería lo que se apreciaría desde el exterior. Posteriormente, en una segunda fase, pero dentro de un período corto de tiempo, junto a ella y cortándola aunque levemente en su extremo suroeste, se construye una nueva tumba, compartiendo la misma orientación. Pero con prefosa y fosa de inhumación central. El cadáver, varón y adulto (Barba Colmenero y Navarro Pérez, 2010), presenta la parte superior del cuerpo en decúbito lateral derecho, mientras que la cadera y las extremidades inferiores adoptan una postura casi prono. No se documenta cubierta para la fosa de inhumación, por lo que pensamos que estaría compuesta por un material perecedero, como la madera. Probablemente ésta estaría formada de una sola pieza o ensamblada de alguna manera que no necesitaría reforzar la unión mediante clavos.

Sería tras este último enterramiento cuando se construye la estructura rectangular de mampostería unida en seco que rodea en parte a las dos tumbas (Castillo Armenteros et al., 2011). Tras las primeras investigaciones se planteó como hipótesis la presencia, como parte de la cubrición final, de un túmulo de tierra (Barba Colmenero y Navarro Pérez, 2010), aunque tenemos

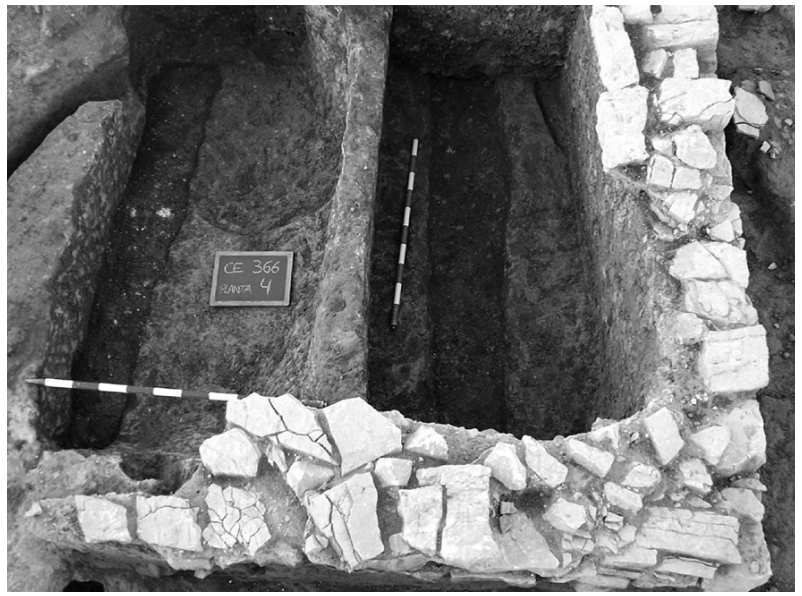

Figura 4: Mausoleo. Futura Ciudad de la Justicia.

que pensar que pudo existir inicialmente una estructura más elevada que desaparecería con el tiempo o que sería eliminada por un motivo que, en principio, no alcanzamos a comprender, pero que podría coincidir con el abandono de la vivienda que se encontraba enfrentada a él. La hipótesis sobre la construcción de un elemento en altura viene dada por la aparición en el nivel que cubre las tumbas de trozos de mortero con impronta de cañizo, lo que nos indica la presencia de algún tipo de cubierta. Esta teoría llevaría a descartar que se tratara de una rawḍ ya que ésta se define como una tumba rodeada por muros pero sin cubrir «asociada de alguna manera a un jardín» (Calvo Capilla, 2014: 227). Tampoco parece que se pudiera tratar de una turba porque esta, generalmente, no estaba cubierta. Por lo que nos inclinamos a pensar que se trataría más de una $q u b b a$, una cúpula sobre los enterramientos. Esta se interpreta como una bóveda celeste que uniría el alma de los muertos, o también la tierra embarazada que dio a luz al hombre y que posteriormente fue devuelto a su útero (Bianquis Thierry, 1994: 214) (Fig. 4).

En cuanto a la distribución del resto de tumbas de la maqbara, en un primer momento de ocupación y fundación de la necrópolis no se observa un diseño previo, todo lo contrario, se pueden apreciar agrupaciones familiares $u$ otro tipo de relaciones sociales. Nos referimos a un momento cronológico que abarca desde finales del siglo VIII hasta finales del siglo IX, en pleno proceso de islamización. Desgraciadamente, en este caso como en la mayoría de cementerios islámicos no hay apenas material asociado que nos pueda ayudar a datar, como veremos más adelante, los enterramientos y tampoco encontramos estelas funerarias como las documentadas en Orihuela (Alicante), formando parte de un panteón o qubba (Martínez Núñez, 2001) que nos ayuden a aportar una cronología aproximada de las mismas. Posteriormente, comienza a planificarse y regularse la colocación de estas tumbas en el espacio, distribuyéndose alineadas y paralelas unas a otras. Se pueden apreciar ciertos espacios que, a pesar de encontrarse en lugares con una alta densidad de enterramientos, están libres, sin ocupar. Lo curioso es que todas estas zonas 


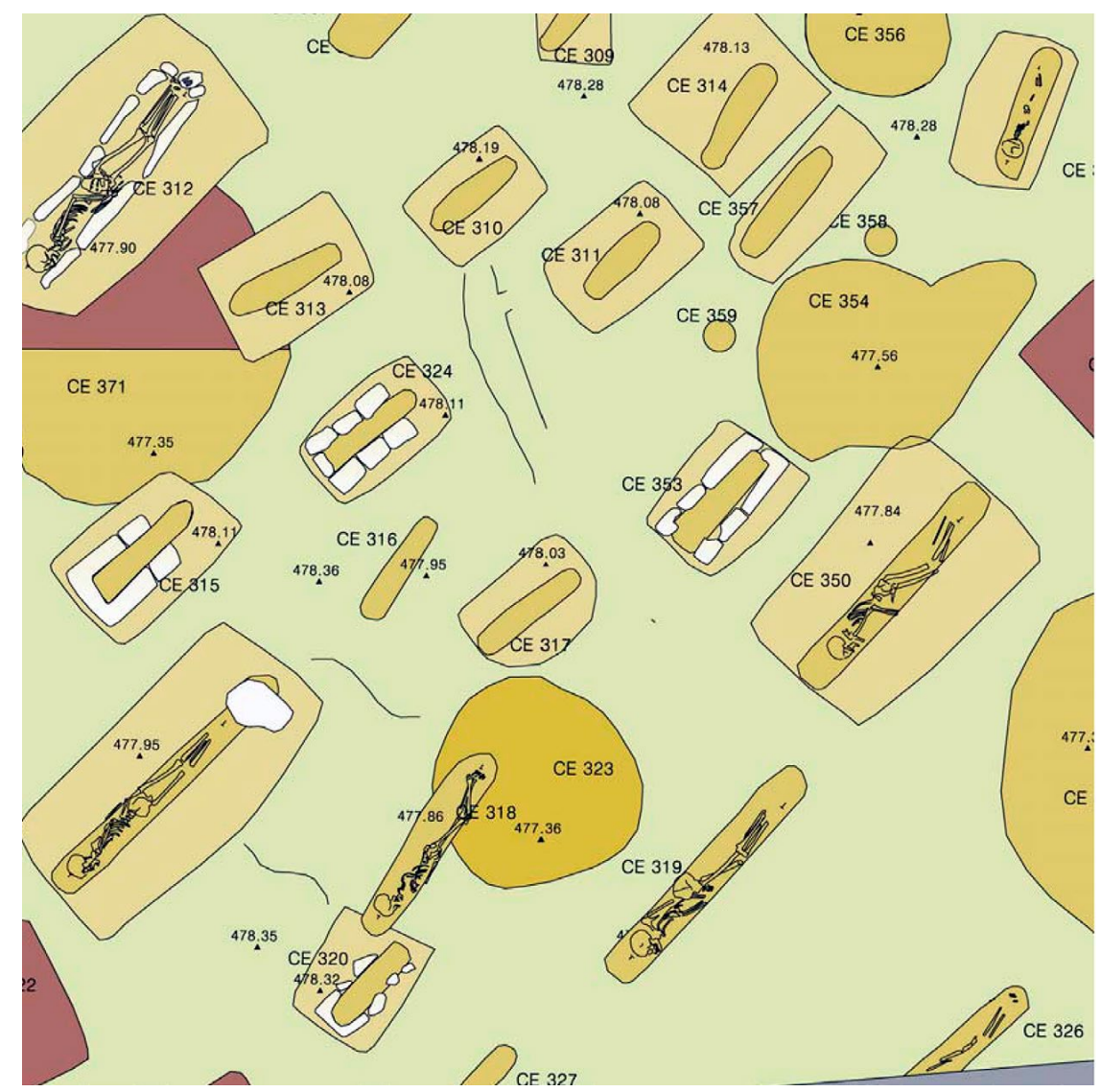

Figura 5: Zona de enterramiento en la que destaca un número mayor de tumbas infantiles.

documentadas, hasta siete, presentan una forma irregular, un área en torno a $4 \mathrm{~m}^{2}$. ¿Se trata de espacios reservados a pequeñas zonas ajardinadas con un árbol de similar porte en toda la maqbara? A nivel arqueológico no se han detectado huellas de una plantación, por lo que deberían ser, si esta hipótesis fuera cierta, plantas de raíces que no implicaran un gran desarrollo.

No tenemos ningún indicio de que haya enterramientos organizados por sexo o por edad, aunque hay concentraciones o agrupaciones de tumbas infantiles. Sin embargo, no creemos que esto signifique que este espacio estuviese reservado a los niños, porque entre ellos, aunque en menor medida, también se encuentran adultos enterrados. Es el caso de las tumbas documentadas en el corte 16 del solar de la futura Ciudad de la Justicia, donde en un espacio de $9 \times 10$ $\mathrm{m}$, se concentran, al menos, 16 sepulturas infantiles rodeadas por cinco de adultos (Fig. 5). Algo similar podemos ver en otras necrópolis de este momento, por ejemplo, en L'Alfossar (Novelda, Alicante), donde «no se ha podido reconocer espacios reservados para cada tipo de enterramiento, no obstante, resulta curiosa la existencia una mayor concentración de inhumaciones infantiles en la zona norte» (López Seguí et al., 2005: 154). Sin embargo, sí hay otras necrópolis en las que se puede apreciar una concentración más clara de individuos infantiles enterrados, es el caso de la maqbara de Pamplona (De Miguel Ibáñez, 2016: 124), la maqbara del Tossal de Manises y en otras: Mérida, Lorca, Jumilla, Albarite de San Juan (Zaragoza), Yecla y Las Cobatillas de Cañete la Real (Málaga) (Tendero Porras et al., 2007: 46). Algunos autores consideran estas concentraciones como una costumbre local ajena a la cultura islámica, o como consecuencia de la alta mortalidad infantil (Tendero Porras et al., 2007: 46). Por lo demás, el tipo de tumba, orientación, cubierta, etc..., no difiere en nada de la de los adultos.

\subsection{Los enterramientos. Tipología}

Las intervenciones arqueológicas desarrolladas en las grandes necrópolis islámicas han presentado desde el principio un gran problema para su análisis histórico, ya que, desde su fundación y hasta su abandono, han perdurado mucho en el tiempo. En este caso, la maqbara de la ZAMB presenta una cronología que va desde los siglos VIII-IX hasta el siglo XIII. La ocupación de un mismo lugar, con una misma función durante más de cuatro siglos, hace difícil discriminar los enterramientos pertenecientes a cada momento histórico. A esto hay que sumar que no contamos con elementos materiales, ni ajuar ni adorno personal que nos ayuden a datarlos. Por último, Marroquíes Bajos en general, presenta poca potencia estratigráfica y con una continua remoción de la tierra por la presencia constante de labores agrícolas. Ante la imposibilidad de presentar materiales asociados que 
aporten cronología, y la imposibilidad de realizar dataciones por radiocarbono, hemos planteado este estudio basándonos en las numerosas variantes detectadas, con el fin de intentar reconocer el momento aproximado de la fundación, y la evolución de la maqbara.

1. Estructura de la tumba: Hay que apuntar que tanto al-Bujārī como al-Qayrawānī en la Risāla describían tres maneras diferentes de excavar la fosa de inhumación. No obstante, estos autores presentan una diferencia, al-Bujārī habla de fosa lahd y šaqq en una sola tumba con dos espacios definidos, mientras que el segundo las describe como dos tipos de tumbas distintas. La fosa definida como darīḥ es citada sólo por al-Bujārī (Chávet Lozoya, 2015: 129). Ateniéndonos a la división realizada por al-Qayrawān̄̄ en la Risāla, en la que las fosas tipo lah̆d y $\breve{s} a q q$ son fosas distintas y siendo conscientes de que no en todas las maqābir andalusíes están representados estos tipos de enterramientos, en la necrópolis a la que se dedica este estudio, hemos distinguido:

Šaqq. Tumba con prefosa y fosa de inhumación central, se caracteriza por la presencia de prefosa rectangular con una profundad que varía entre 0,15 y 0,50

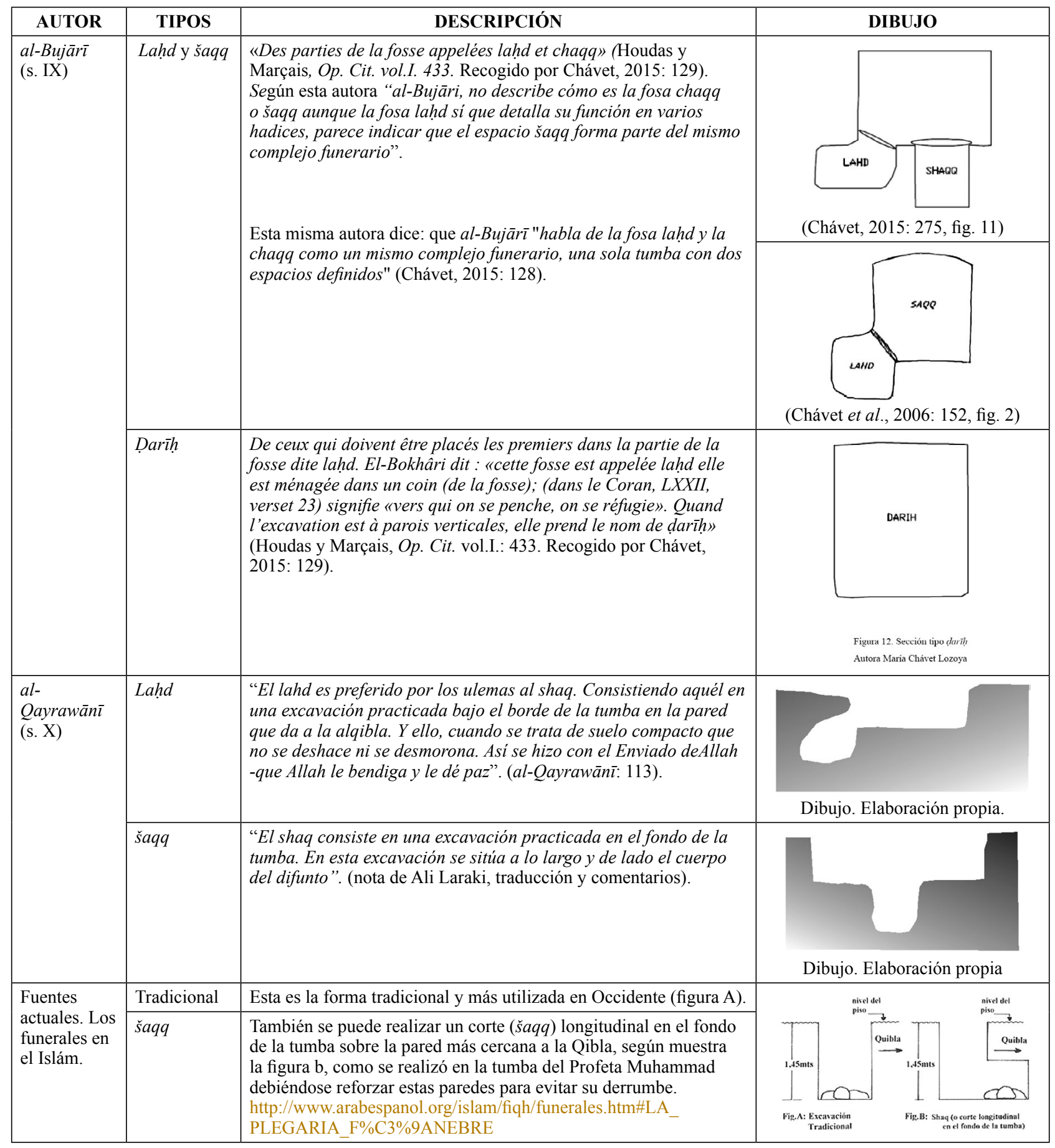

Figura 6: Tipo de tumbas según las fuentes. 


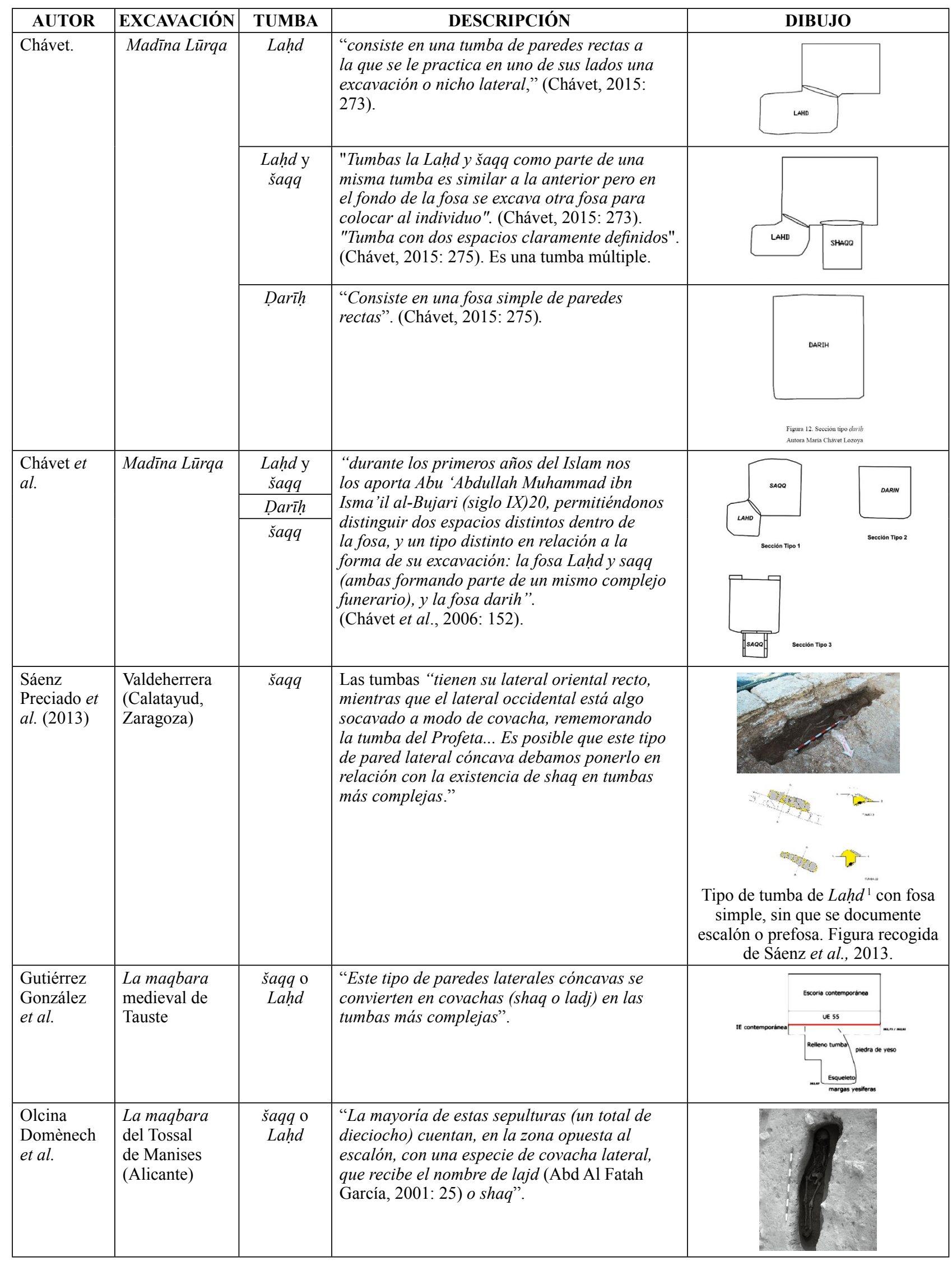

Figura 7: Tipo de tumbas. Interpretaciones.

1. En la publicación a la que pertenecen estas imágenes de la necrópolis de Valdeherrera en Calatayud, al referirse a este tipo de tumba la denomina šaqq, "Tumba 31, empleando el muro de sillares a modo de šaqq. Como veremos seguidamente esta problemática tiene su origen en las diferencias de interpretación o descripción de al-Bujārī y al-Qayrawāni. 
$\mathrm{m}$, en cuyo centro se practica una estrecha fosa de inhumación. Ésta aparece representada, aunque con ciertas variaciones, en la mayoría de las necrópolis (cristianas e islámicas) estudiadas en Marroquíes Bajos (Fig. 6 y 7).

No obstante, a pesar de que parece estar mejor representada en el mundo preislámico constatamos que, tanto durante el proceso de islamización como después de él, este tipo de sepultura sigue estando vigente de forma significativa, con un total de 173 enterramientos, lo que supone el $27 \%$ del total de las fosas identificadas y distribuyéndose espacialmente por casi toda la maqbara, de norte a sur (Castillo Armenteros et al., 2011), aunque conforme nos alejamos del límite del camino y nos adentramos hacia el este, las sepulturas de estas características van desapareciendo, y de hecho, es el único tipo que apenas está representado en el futuro solar de la Policía Local (Fernández Ordóñez et al., 2010). La profundidad de la prefosa varía según
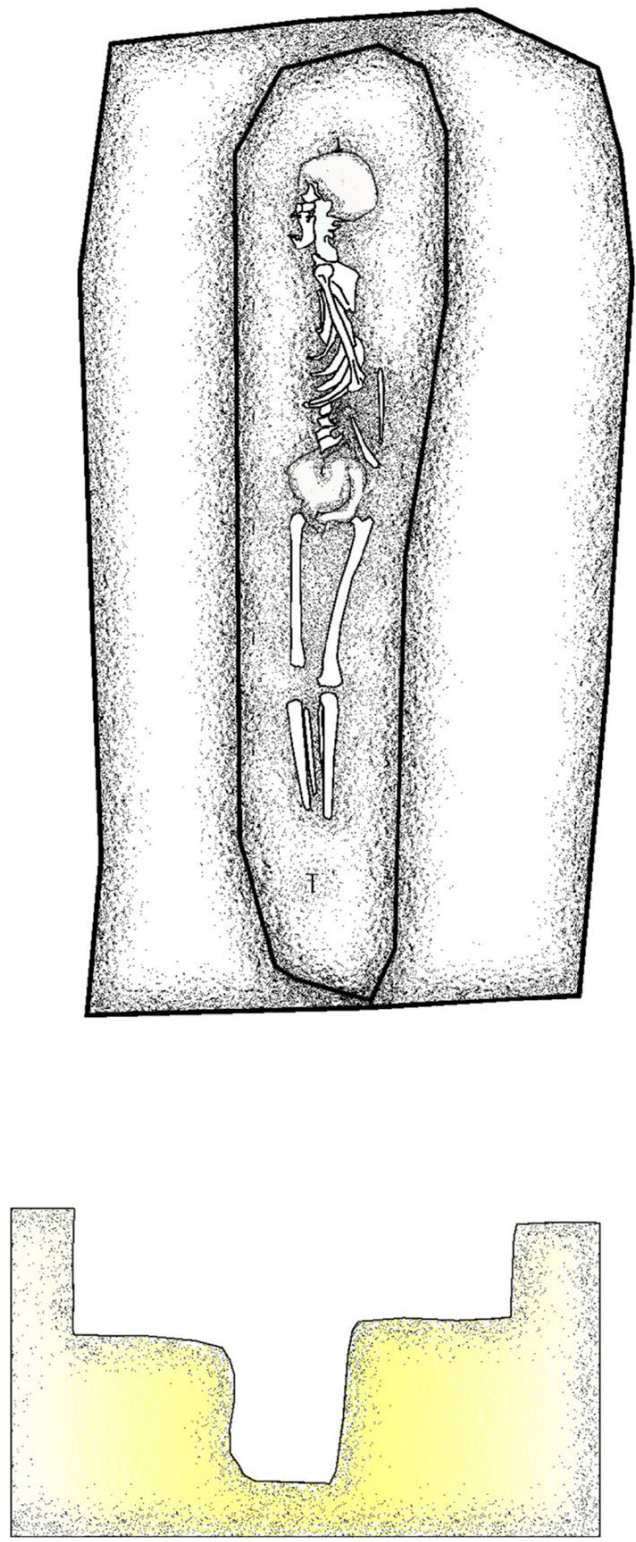

Figura 8: Tumba tipo šaqq. Ciudad de la Justicia. ZAMB. su posición espacial en la necrópolis, conforme nos acercamos al camino de Bayyāsa y, sobre todo, en la zona norte, junto al mausoleo o qubba, es más profunda, alcanzando el máximo en la T 393 perteneciente a dicha estructura, que tiene $0.50 \mathrm{~m}$ de profundidad en prefosa y $0.45 \mathrm{~m}$ de fosa de inhumación.

Este tipo de fosas (Fig. 8) tienen una tradición oriental, era costumbre en la Meca a diferencia del tipo lahd, y que veremos posteriormente, era utilizado en Medina (Bianquis Thierry, 1994), lo que no invalida la teoría defendida por Serrano y Castillo (2000) de que se trata de un tipo de enterramiento utilizado mayoritariamente por hispanovisigodos convertidos, que encontrarían en estos enterramientos una continuidad con sus tradiciones que conjugan perfectamente, sin entrar en contradicción con los nuevos preceptos canónicos. Esta tipología de fosas se puede reconocer en las necrópolis de Marroquíes Bajos de rito cristiano pero siempre con la cabecera marcada. También encontramos paralelos, aunque escasos, en otras necrópolis de al-Andalus, en el Cabezo de Aljezar (Ricote, Murcia) (Serrano Peña y Castillo Armenteros, 2000), y también, en la maqbara de Pamplona, datada en el siglo VIII, donde se ha documentado un caso de este tipo de enterramiento, T 194, consistente en una prefosa central o šaqq, en la que según la documentación gráfica y fotográfica aportada por De Miguel Ibáñez (2016: 619) la profundidad de la prefosa es mediana y está excavada en terreno no demasiado compacto. Puede ser éste el motivo de que el resto de tumbas pertenezcan al tipo de fosa simple o al estar excavada en la tierra apenas sea reconocida como ocurre en la calle Cava, en Lorca (Martínez Rodríguez y Montero Fenollós, 1996), y en la maqbara del Tossal de Manises (Olcina Domènech et al., 2008).

Pero dentro de los enterramientos tipo $\check{s} a q q$, aparecen variantes:

- A. Tipo $\check{s} a q q$, donde la prefosa puede variar en anchura, algo que parece coincidir con diferentes orientaciones y posición dentro de la maqbara.

A.1. Son las más anchas (una media de 1,45 m), localizadas en el área sur y con una orientación de tendencia sur, cuadrante SE.

A.2. Las más estrechas (en torno a $1 \mathrm{~m}$ ) se sitúan en el norte, junto al límite del camino, con una orientación de tendencia este.

A.3 Por último, hay que señalar que nos encontramos con otras cuya anchura de fosa se halla entre ambas, situadas en la zona central y más alejada de los límites del camino de Bayyāsa.

- B. Tumbas de tipo šaqq que presentan la huella de parihuelas sobre la fosa de inhumación, elemento que solo aparece en este tipo de tumbas. En realidad, su presencia es muy poco significativa, ya que sólo se ha documentado en dos tumbas pertenecientes a época califal.

Lahd. Tumba con prefosa y fosa de inhumación lateral, también se le denomina de fosa lateral. La tumba 


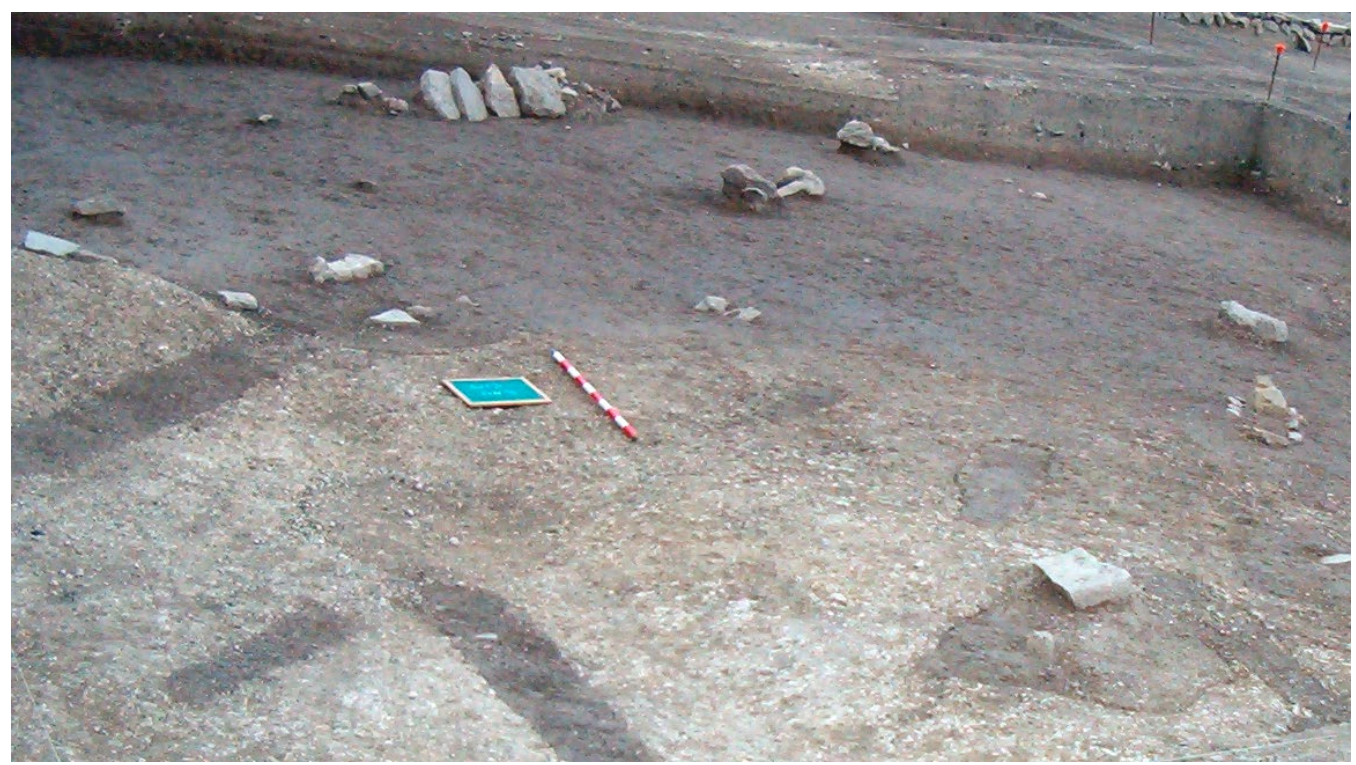

Figura 9: Ciudad de la Justicia. Corte 13. Enterramientos sobre el tercer foso calcolítico.

está caracterizada por una prefosa similar al tipo anterior, la diferencia radica en que la fosa de inhumación se sitúa en el lado este. Dentro de este tipo, tendremos que diferenciar aquellas en las que la fosa de inhumación puede estar aboveda, de aquellas otras en las que la misma se simplifica convirtiéndose en una simple (Castillo Armenteros et al., 2011). En el caso de Marroquíes Bajos, de todas las necrópolis medievales documentadas, sólo la gran maqbara presenta fosas de este tipo, y por tanto sólo aparece en tumbas con ritual islámico. Representa el grupo menos numeroso con un $11,5 \%$ del total y se distribuye espacialmente por toda la necrópolis, aunque con mayor concentración en los sectores norte y central, mientras que en el sur se encuentran más dispersas (Castillo Armenteros et al., 2011). Las diferencias que podemos observar dentro del tipo de tumba lahd se refieren fundamentalmente, como en el caso anterior, a la profundidad de la prefosa. Al igual que pasaba en las tumbas tipo $\check{s} a q q$, las prefosas más anchas, en torno a 1,50 m, se encuentran en el sur, aunque en un número muy escaso. Las más estrechas, 1 $m$ aproximadamente, se sitúan en el extremo norte junto al mausoleo, formando dos grupos, uno de 16 tumbas y otro de ocho enterramientos localizados a $16,5 \mathrm{~m}$ al sur del anterior. Todas ellas con una orientación de tendencia Este. Por último, encontramos las tumbas con prefosa, de unas dimensiones medias de 1,20 m, localizadas en una zona intermedia y más alejadas del límite del camino de Bayyāsa. La orientación varía entre la tendencia de compromiso y la cordobesa. Como vemos, todo ello es similar a lo que pasaba en el caso anterior de tumbas de tipo $\check{s} a q q$. La diferencia estriba en su localización, mientras que hay un mayor número de las de tipo $\check{s} a q q$ en el sur, las de tipo lah̆d lo hacen en el norte. En cuanto a la profundidad de la prefosa, no varía demasiado de unas a otras, siendo relativamente poco profunda, entre 0,15 y $0,20 \mathrm{~m}$, a excepción de las tumbas pertenecientes al mausoleo, ambas en torno a los $0,35 \mathrm{~m}$.
Aún hay que introducir un nuevo aspecto, que en este caso atañe a la propia fosa de inhumación colocada al este, y que depende de la forma de la covacha, incluso de su existencia o no, lo que nos aporta diferentes tipos de tumbas:

- A: Fosa de inhumación dentro de la prefosa ligeramente desplazada hacia el este, sin llegar al límite de ésta. De los cuatro casos que presentan este tipo, tres pertenecen a tumbas infantiles y una a adulto.

- B: Prefosa muy estrecha y fosa lateral sin covacha.

- C: Prefosa y fosa lateral sin covacha. Distribuidas prácticamente en toda la necrópolis y con todo tipo de orientaciones.

- D: Fosa lateral con indicios de covacha.

- E: Fosa lateral con covacha totalmente subterránea. Se localiza en prácticamente toda la necrópolis.

- F: Fosa simple sin prefosa pero con indicios de covacha o cámara lateral.

Según al-Bujārī, esta tumba era la idónea, mientras que otro tipo de fosas, como el šaqq, se realizaría sólo cuando no se pudiera construir el laḥd por peculiaridades del terreno. En realidad, la base geológica en la ZAMB se encuentra muy superficial, extendiéndose por casi toda el área del cementerio, excepto en aquellos lugares donde localizamos estructuras prehistóricas excavadas en la base geológica, como es el caso del tercer foso de la macro-aldea de Marroquíes Bajos (Fig. 9). El área donde se localiza este es el espacio más extenso en el que la base geológica no es superficial y, por tanto, el lugar donde es más difícil construir tumbas tipo lahd por el peligro de derrumbe que entraña. Probablemente por ello la ocupación se redujo considerablemente y las tumbas documentadas han sido en casi todos los casos, de fosa simple. La menor presencia de enterramientos tipos lahd, puede deberse a la existencia de niveles no aptos para ella. 
Las maqābir donde se documentan tumbas con esta estructura tipo lahd, a diferencia de las de tipo $\check{s} a q q$, son abundantes, abarcando una cronología muy amplia. Aquí señalaremos algunas de ellas: las excavadas en Lorca junto a la iglesia del Carmen, la de Tauste (Zaragoza), datadas entre los siglos VIII-XI (VigilEscalera, 2015); las de Segóbriga (Cuenca) y las de Mérida, donde de un total de 200 inhumaciones, se han documentado 80 de este tipo datadas cronológicamente entre los siglo VIII-IX. Estas tumbas contienen cuerpos colocados en decúbito supino, por lo que sus excavadores, según recoge Vigil-Escalera (2015), lo interpretan como enterramientos cristianos de época andalusí. El Tossal de Manises, donde se excavaron 18 tumbas de tipo lahd (Olcina Domènech et al, 2008); en la Bāb Baŷŷāna en Almería, (Olcina Domènech et al., 2008); en L'Alforsar en Novelda (Alicante) se documentan un total de 177 enterramientos de fosa excavada en la roca, todas ellas según sus excavadores de época almohade: «destaca la existencia de una serie de tumbas que tenían una boca estrecha y una base más ancha, que se conseguía tras excavar en la pared oriental para colocar alli al individuo, dando un aspecto de una especie de hornacina o nicho que se tapaba con las lajas de piedra inclinadas, sellando el interior de la tumba y dando lugar a una fosa de sección trapezoidal con el lado oriental siempre en vertical-inclinado mientras que el oriental estaría recortado» (López Seguí et al., 2005: 149). Hay otras necrópolis en las que se han documentado enterramientos de este tipo y que presentan cronologías más tardías, como el Cerrillo de Mondújar en Granada de época morisca, siglo XVI (Chávet Lozoya, 2015: 322).

Tipo darịh o tumba de fosa simple: se documenta en todas las necrópolis medievales de la ZAMB, tanto de rito cristiano como de rito islámico. En la maqbara del camino de Bayyāsa es el tipo más abundante, con un total de 395 enterramientos, lo que supone el $61 \%$, distribuyéndose por toda el área de enterramiento e incluso en las tumbas que se sitúan, en época tardía, fuera de él, pero en su entorno más inmediato. Las variantes sobre el tipo de fosa simple o darịh son mínimas, no se aprecian grandes diferencias en la profundidad. Esta suele oscilar entre los 0,35 y los $0,45 \mathrm{~m}$. Sólo podemos observar variantes en su orientación. En cuanto a los paralelos existentes sobre este tipo de fosa en las maqābir andalusíes, hay que decir que éste es el más difundido ya que aparece prácticamente en todos los cementerios de estos momentos, bien conviviendo con otros tipos de fosas, como los que ya hemos visto, o en necrópolis en las que sólo se documenta este tipo. Es el caso, por ejemplo, de las excavadas en Córdoba; a pesar de las numerosas intervenciones arqueológicas en las que se han documentado enterramientos, todos ellos son de tipo de fosa simple, con numerosas variantes en cuanto a características de sus paredes y fondo o cubiertas, señalizaciones y orientación (Casal García, 2003).

\subsection{ORIENTACIÓN}

Una vez que conocemos los diferentes tipos de fosas de enterramientos que se han excavado en la maqbara del camino de Bayyāsa, tenemos que centrarnos en otra de las variantes a tener en cuenta en el estudio de la estructura funeraria, como es la orientación de las tumbas. Rius, en su estudio sobre la alquiba, resta importancia a la orientación de las tumbas, ya que las referencias a ésta son escasas: «Averroes expone que no hay acuerdo sobre la necesidad de colocar el muerto en dirección de la quibla, y que Māliki refería que esta práctica no era antigua, puesto que no se había transmitido en ninguno de los șahāba, ni de los tābicūn que fuese obligatorio el tawŷih » (Rius, 2000: 95). A pie de página indica que «para el investigador es dificil sacar una información certera de la posición de las tumbas, básicamente por dos razones: a) en el caso de los cementerios los criterios de orientación son más laxos que en la edificación de las mezquitas y, en numerosas ocasiones la disposición del terreno define la disposición final; b) no hay unanimidad entre los musulmanes sobre qué parte del cuerpo es la que debe de apuntar realmente hacia la Kacba: los pies o el rostro (que se encuentra girado)» (Rius, 2000: 95). No obstante, hay que admitir que aunque no hubiera necesidad, la práctica era común, ya que resulta significativo que las diferentes orientaciones referentes a las mezquitas de al-Andalus expuestas en su trabajo coinciden con el abanico de posibilidades documentado en esta necrópolis (Castillo Armenteros et al., 2011). Por otro lado, hay que tener en cuenta que la disposición de las tumbas según la propia configuración del terreno, de caminos y de cursos de agua, es algo que se ha defendido ampliamente en ésta y otras necrópolis. En Marroquíes, las primeras investigaciones apuntaban a que las tumbas pertenecientes a una primera fase estaban orientadas «según el eje marcado por los arroyos y canales entre las elevaciones naturales del terreno. El criterio parece haber sido más funcional que religioso» (Serrano Peña y Castillo Armenteros, 2000: 99). Algo que como vimos debe de ser matizado a la luz de los nuevos datos aportados en las nuevas excavaciones. Otros autores interpretan estas diferencias en la orientación como consecuencia de variaciones estacionales (León Muñoz, 2008-2009; Casal García, 2003). También se ha puesto en relación la orientación de las tumbas con elementos arquitectónicos como son las mezquitas. Siguiendo este criterio, se propone que las tumbas emirales serán aquellas que tienen una orientación E-W, coincidiendo con la quibla de las mezquitas de este período que, posteriormente a partir del siglo X serán corregidas (Alba Calzado, 2005; León Muñoz, 2008-2009). Probablemente este aspecto haya que tenerlo en cuenta, sobre todo en cementerios cercanos a ellas. De hecho, los enterramientos que hemos documentado en el interior de la mezquita situada en Marroquíes, aunque para una fase tardía, de época almohade, se encuentran orientados totalmente perpendiculares a la quibla. Por tanto, la diversidad de 


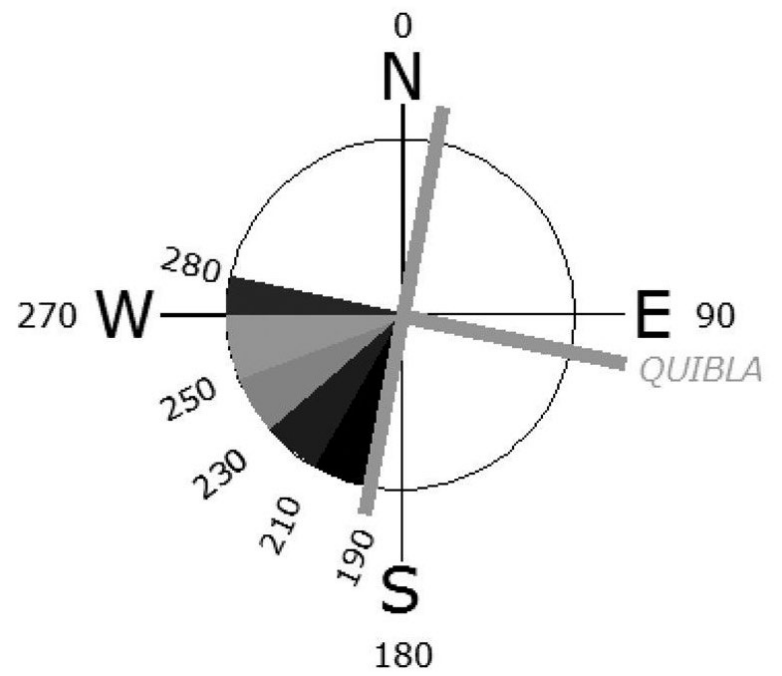

Figura 10: División. Orientaciones documentadas en la maqbara del camino de Bayyāsa.

orientaciones dentro de un mismo cementerio necesita de éstas y otras explicaciones. Vamos a realizar un recorrido por las orientaciones documentadas en esta necrópolis, poniéndolas en relación con su localización $\mathrm{y}$ otras variantes.

Entre las 645 inhumaciones estudiadas podemos establecer cinco agrupaciones (Fig. 10) que, según su orientación, abarcan un ángulo que oscila desde los $195^{\circ}$ a $285^{\circ}$ respecto al norte. Teniendo en cuenta que la quibla en la ZAMB, y en general en Jaén, está a $101^{\circ}$, la perpendicular se encontrará entre $191^{\circ}$, donde se sitúa la cabeza y los $11^{\circ}$, donde están los pies de la tumba. Esta dirección marcaría la orientación correcta o canónica a la que deberían ajustarse todos los enterramientos. Basándonos en la división realizada por

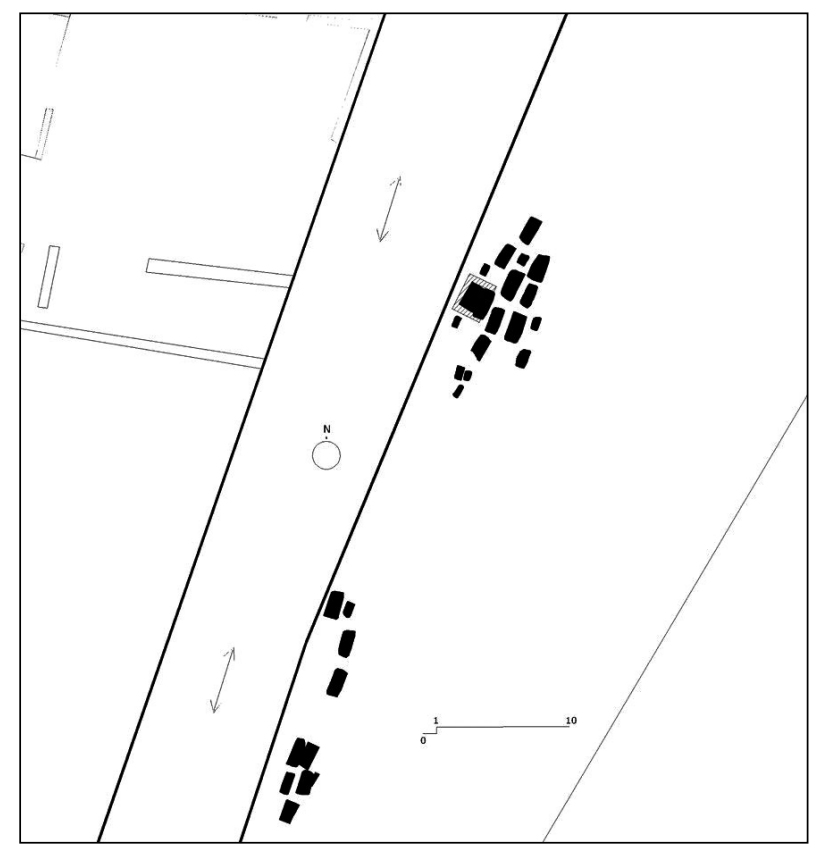

Figura 11: Localización de tumbas con orientación Tendencia Este.
M. Rius (2000) para las mezquitas, y siempre atendiendo a que estamos hablando de tumbas y, por tanto de la perpendicular a la quibla, hemos realizado cinco divisiones.

A.- Tumbas que están orientadas perpendiculares a la quibla con Tendencia Este (Fig. 11). Los enterramientos que tienen esta dirección serían hipotéticamente los mejor orientados de toda la maqbara. El número de este tipo es muy limitado, 40 , lo que supone un $6,2 \%$ del total. Lo más llamativo es su localización junto al límite del camino y en la zona norte de la necrópolis, enfrentada a la única vivienda que en época emiral existe en la zona. A este grupo pertenece el mausoleo o qubba del que ya hemos hablado y las tumbas que se encuentran junto a él. Al sur de éste, otro conjunto de 10 enterramientos de adultos y dos infantiles, con las mismas características, pero esta vez prácticamente alineados con el camino. Y por último existe otro pequeño grupo de cuatro enterramientos, con esta misma disposición, todos ellos infantiles y exclusivamente de fosa simple, que se localiza un poco más alejado del límite del camino.

B.- Tumbas que están orientadas perpendiculares a la quibla con Tendencia SE (Fig. 12), también llamada de compromiso, siendo válido al aplicarse yiha, como dirección general, que puede abarcar un margen de hasta $180^{\circ}$, en contra de la 'ayn, dirección exacta (Rius, 2000: 20). Con un total de 284 enterramientos, que suponen el $44 \%$ del total. Se localizan en toda la maqbara, aunque en la zona sur su presencia es insignificante y cuando aparecen son siempre de fosa simple pertenecientes a una época muy tardía. Igualmente, con esta orientación, están representados todos los tipos de fosa šaqq, laḥd y darīh, así como sus variantes.

C.- Tumbas que están orientadas perpendiculares a la quibla, cuando ésta es considerada a $150^{\circ}$, o similar. Rius (2000: 113) establece esta tendencia a partir de la quibla de la aljama de Córdoba, orientada a $152^{\circ}$,

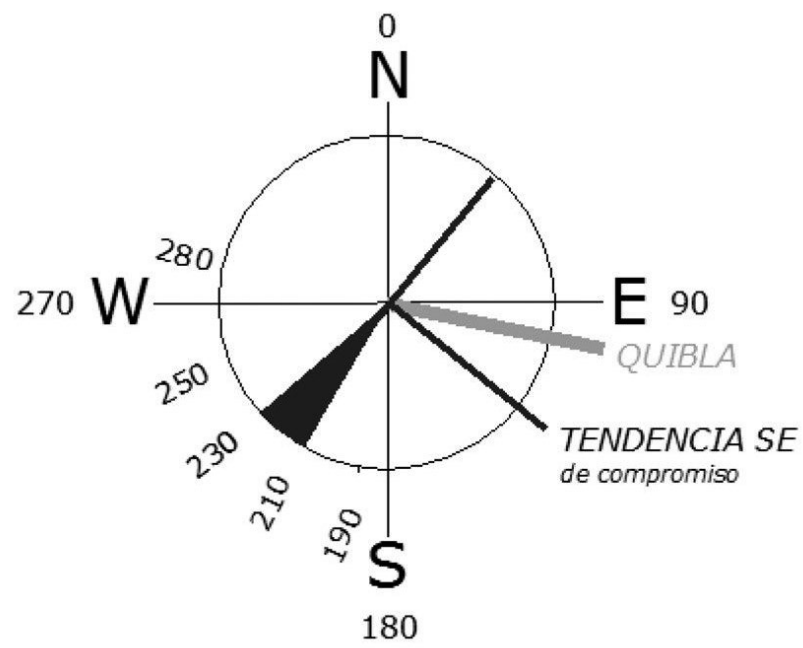

Figura 12: Orientación Tendencia SE. De compromiso. 
denominándolas de Tendencia Cordobesa. Este tipo presenta un total de 204 enterramientos, lo que supone el 31,62\% del total. Se localizan en toda la maqbara, su distribución es muy similar a la anterior, la diferencia es que las de Tendencia Cordobesa están mejor representadas en el lado sur de la necrópolis. En cuanto al tipo de fosa más utilizada con esta orientación, es la fosa simple (86), seguida de la central (43) y para terminar la fosa lateral está escasamente representada (6).

D.- Tumbas que están orientadas perpendiculares a la quibla, cuando ésta es considerada entre $160^{\circ}$ y $180^{\circ}$ Tendencia Sur, cuadrante SE. Las tumbas, por tanto, estarán en un cuadrante entre $250^{\circ}$ y $270^{\circ}$. Las sepulturas con esta orientación se concentran casi exclusivamente en el centro sur de la maqbara y junto al camino de Bayyāsa. El número total, 100 tumbas, supone el 15,5\% de las documentadas y, según la tipología de la fosa, la gran mayoría son šaqq, seguida de fosas simples y, por último, las fosas de tipo lahd, de las que tan sólo tenemos ocho.

E.- Por ultimo, trataremos las tumbas que están peor orientadas de todas las representadas en la necrópolis. Se trata de tumbas alineadas perpendiculares a la quibla, cuando ésta es considerada entre $180^{\circ}$ y $200^{\circ}$, Tendencia Sur, cuadrante $S W$. Las tumbas, por tanto, estarán en un cuadrante entre $270^{\circ}$ y $280^{\circ}$. Son, con diferencia, las menos numerosas, con un total de 18 enterramientos. Se localizan todas, excepto una, en la zona central de la maqbara y junto al camino. En lo que tiene que ver con su morfología, sólo tenemos tumbas de fosa central o $\check{s} a q q$ (tres) y el resto son de fosa simple, de éstas seis son infantiles y un adulto.

\subsection{TIPOS DE CUBIERTA Y SEÑALIZACIÓN}

A pesar de que lo más habitual es la simplicidad de las tumbas, hay un número importante en el que se aprecian elementos de cubierta y, en menor medida, de señalización. Hay que tener en cuenta un dato importante, muchas de las tumbas documentadas en las que destaca la simplicidad y ausencia de señalizaciones, pueden aportar una imagen falsa de lo que en realidad fue, por varias razones entre ellas:

- Los materiales funerarios fueron sistemáticamente expoliados y reutilizados en edificios de nueva construcción desde los primeros años de la conquista cristiana, algo que continuaría en los siglos posteriores (Martínez Núñez, 2011).

- Los elementos funerarios, como epígrafes de un alto valor artístico y, sobre todo, histórico, fueron botín de numerosos anticuarios que, como en el caso anterior, fueron motivo continuado de expolio (Martínez Núñez, 2011).

- Las remociones de terreno en espacios agrícolas han hecho que muchas de estas señalizaciones desaparecieran, incluso pasaran desapercibidas en el caso de estar constituidas por elementos de piedra, teja o similar.

- Algunas de las señalizaciones podían estar compuestas por materiales perecederos.

- Por último, tenemos que señalar que la causa de la desaparición de estos elementos pueden ser causas naturales. En el caso de Marroquíes Bajos, sabemos que se produce un momento de abandono de la necrópolis con la crisis del califato y que no se volverá a ocupar hasta el siglo XII. Este prolongado abandono hizo que se desbordasen los arroyos y se abriesen «numerosos regueros, que alteraron o rellenaron antiguos cauces. Esto provocó la erosión de los túmulos funerarios, de fases anteriores, incluso pudo arrasar con cualquier señalización» (Serrano Peña y Castillo Armenteros, 2000: 102).

En la maqbara del camino de Bayyāsa existen numerosas variantes de cubiertas y señalizaciones, tejas, adobes en torno a la fosa o en los laterales de ésta; piedra en los pies, en la cabecera, en los pies y la cabecera, en los laterales, y por último un gran número de enterramientos en los que no han aparecido ninguno de estos elementos. Por otro lado, hay que indicar la presencia de parihuelas en alguna de las tumbas. Pero el aspecto externo de casi todas ellas debería ser el mismo, un pequeño túmulo de tierra (Castillo Armenteros et al., 2011).

En primer lugar, nos centraremos en las cubiertas. Algunos autores (Ruiz Tabeada, 2014) indican que las fosas de inhumación tenían dos cierres o cubiertas: uno subterráneo y otro superficial; para el primero se utilizaban diferentes materiales, como los ya señalados para nuestra maqbara. Fierro (2000: 178) indica que los mālikíes preferían materiales sólidos, adobes (libn), tablas de madera (alwāhh), tejas (al-qarāmìd), ladrillos (âyurr) y piedras. De estas dos cubiertas, generalmente, al menos en la zona a la que va dedicado este estudio, la que cubre la fosa de inhumación es la formada por elementos como la madera, que en muchos casos se sujeta con losas de piedra o adobes y, en otros casos, la fosa era cerrada por medio de tejas, etc... Sin embargo, el segundo cierre estaría compuesto por un túmulo de tierra que caería directamente sobre la primera cubierta. Los preceptos religiosos indicaban que había que dejar la fosa o cámara hueca de tal forma que el individuo fallecido se levantara ante el juicio de los ángeles Munkar y Nakīr (Gutiérrez González et al., 2016: 435).

En cuanto a la señalización, la ausencia de elementos que distingan un enterramiento son los indicadores más característicos y representativos de nuestra necrópolis, afectando a un $97 \%$. Lo más probable es que las tumbas tuvieran un pequeño túmulo levantado sobre la rasante de la calle y que ésta fuera la única muestra de la existencia de un enterramiento. No obstante, tenemos casos en los pueden intuirse otros elementos, por ejemplo, en la T 24, sobre la fosa de inhumación se documenta una piedra en los pies; ésta, por su tamaño 
y dado que la prefosa tiene una escasa profundidad, podría emerger del túmulo si éste no era demasiado elevado, teniendo por tanto dos funciones: la de sujetar la tabla o madera que cubriría la fosa de inhumación y a la vez de señalización de los pies de dicho enterramiento.

Otras veces sí que se documentan verdaderas señalizaciones con losas de piedra colocadas de forma casi vertical, a modo de tejado a un agua, sobre el relleno de tierra que cubriría la cubierta de la fosa de inhumación. Pero este tipo de señalización nos lleva a hacernos una pregunta, ¿cómo estas piedras, colocadas de forma casi vertical, no sufrieron movimiento al descomponerse la madera o similar y rellenar la fosa de inhumación donde se encontraba el cadáver? Ante esto, tendríamos que preguntarnos si, en algunos casos, las fosas fueron rellenas de tierra en el mismo momento del funeral, desoyendo así los preceptos religiosos, algo que es defendido por algunos autores para otras necrópolis, como es el caso del cementerio de Tauste (Gutiérrez González et al., 2016). A veces se han documentado piedras en los pies o en la cabecera que se han interpretado como señalizaciones de la tumba. No obstante, creemos que no tienen la entidad ni el tamaño para cumplir esta función, quedando probablemente englobadas o embutidas en el interior del túmulo y, por tanto, formarían parte de la primera cubierta o fosa de inhumación, no como señalización, sino de sujeción de un elemento perecedero que serviría de cubierta. El problema de esta hipótesis, en el caso de las piedras en los pies y en la cabecera, es el mismo que planteábamos antes al descomponerse la cubierta de la fosa de inhumación, ¿cómo es que ésta no cede cayendo al interior de la fosa? Esta duda se puede plantear tanto si sirve de sujeción como si es de señalización.

Las tumbas debían de ser visibles de alguna manera, ya que en la gran mayoría de los casos no hay intersecciones entre fosas ni superposiciones, aun cuando el cementerio tiene una vida prolongada, incluso con pequeños o grandes momentos de abandono.

En cuanto a las cubiertas de la fosa de inhumación, la ausencia de éstas es la más documentada con 552 tumbas de un total de 643. La no documentación de éstas no significa su ausencia, sino que mayoritariamente, como nos indican los registros arqueológicos, estaban construidas con materiales perecederos, madera $u$ otros vegetales como cañizo o similar y no nos ha llegado, pero es necesario, al menos siguiendo los preceptos religiosos, su presencia para que mantenga el cadáver en un espacio hueco, para que el difunto se levante ante el interrogatorio de los ángeles. No obstante, según indican Tendero Porras et al. (2007: 43) «esta interpretación, tiene una duración determinada y no muy larga, si tenemos en cuenta que el conjunto de pruebas que ha de superar el alma se realiza en cuarenta días. Se puede pensar que este corto espacio de tiempo, de unas pocas jornadas, no precisa necesariamente la existencia de fosas de características especificas, ni de complejas cubiertas que aíslen al difunto».
En el caso de las tumbas infantiles y de los mártires, se considera que no son pecadores, y entonces no serán interrogados por Munkar y Nakīr, sino que «las almas de los niños musulmanes están en los buches de los gorriones que pastan en el Paraíso donde quieren» (Chávet Lozoya, 2015: 168). Por tanto, no es necesario que la fosa sea un espacio hueco.

En algunas necrópolis se han hallado pequeñas oquedades excavadas junto a las tumbas, que tiene que ver, según Chávet (2015: 156), con este hadīt de los pájaros verdes. Por ejemplo, en el cementerio de la Puerta de Purchena en Almería, se documentan en las fosas «huecos o tazones» que aunque su excavadora, C. Peral, pone en relación con un ritual de purificación islámico donde los huecos serían para la captación del rocío, Chávet (2015: 172) lo relaciona directamente con este hadīt. Esta misma autora indica ejemplos de otros cementerios donde se ha documentado: Ardales (Málaga), Revenga y Cillaperlata en Burgos, Campo la Puerta, Las Henestrosas en Cantabria y Murcia, junto a la muralla árabe. En el caso de Marroquíes Bajos, durante el trabajo de campo de dicha intervención arqueológica no se identificó ningún elemento con esta funcionalidad; se documentaron numerosos huecos dentro de la zona de la necrópolis, que fueron interpretados mayoritariamente como hoyos de poste de la fase calcolítica, que tiene una densidad de estructuras muy importante. En una nueva revisión de la documentación, fichas de registro, documentación gráfica y fotográfica, hay algunos de estos elementos que pudieran estar íntimamente relacionados con algunas de las sepulturas. Por ejemplo, la T 14 tiene junto a ella un hueco circular, de apenas $0,15 \mathrm{~m}$ de diámetro en su parte más ancha, que podría tratarse del hueco para contener un pequeño cuenco de cerámica o similar, del que no ha quedado rastro. Otro de estos elementos puede ser un surco circular similar al anterior, aunque un poco más ancho, 0,25 $\mathrm{m}$ de diámetro. Se sitúa en una zona, corte 16 del solar de la Ciudad de

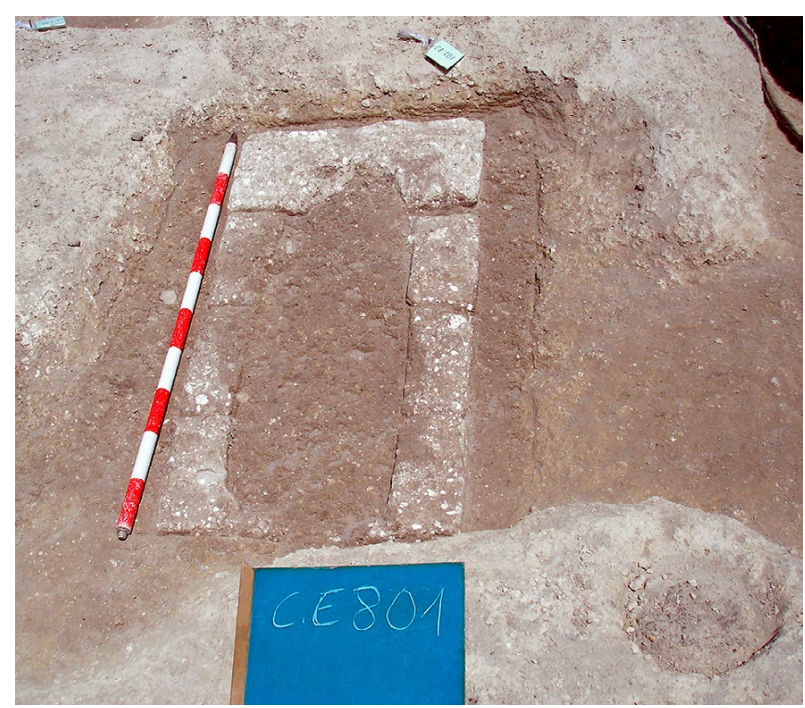

Figura 13: Tumba 14. Futura Ciudad de la Justicia. 
la Justicia, en la que hay una concentración de enterramientos infantiles importante, como ya adelantamos cuando hablábamos de la distribución interna de la necrópolis. Por otro lado, cabe destacar que del tipo de sepulturas que se concentran en este espacio, tres tienen en común que están bordeadas de adobes, algo que también comparte la T 14 (Fig. 13). Además, la mayoría son de tipo $\check{s} a q q$. Tenemos, al menos, cuatro casos más, las Tumbas 6, 60, 95 y 436. No se descarta que hubiera más surcos de este tipo, que no han podido ser identificados en esta fase de revisión de la documentación.

Volviendo al tipo de cubiertas, la presencia de clavos en el interior de algunas tumbas confirma la existencia de una estructura de madera, de tablas y raramente con la presencia de ataúd, que aunque la tradición islámica lo prohíbe (Olcina Domènech et al., 2008) se utilizan en algunos casos. De hecho, es una práctica que empieza a generalizarse a partir del siglo XI-XII, ensanchándose con ellos las fosas de inhumación y documentándose clavos en su interior. Práctica que se realiza como medida higiénica ante la superpoblación de los cementerios (Casal García, 2001).

Sin embargo, la presencia de clavos en esta necrópolis es muy escasa y en ningún caso parece que esté relacionada con la existencia de ataúdes, sino con el ensamble de tablas de madera que conformarían la cubierta de la fosa de inhumación o la presencia de parihuelas. Algunos autores han puesto también en relación la presencia de clavos en el interior de la fosa de inhumación con la presencia de maderas colocadas bajo el difunto para mantener la posición del cuerpo y del rostro, aunque lo habitual es colocar otro tipo de elementos, como cerámica o piedras a modo de calzos (León Muñoz, 2008-2009).

La presencia de clavos se ha documentado en necrópolis como la de Pamplona (Vigil-Escalera, 2015), en la Iglesia del Carmen (Lorca) donde se documentaron 11 sepulturas (Chávet Lozoya, 2015). Dos en la necrópolis de L'Alforsar (Novelda, Alicante) (López Seguí et al., 2005). En Córdoba, en las excavaciones realizadas en la Ronda de Ponient (Casal García, 2003). También se ha detectado la presencia de clavos en el interior de las fosas de inhumación en la necrópolis de Fuerte de Santiago (Algeciras, Cádiz) (Tomasseti et al., 2005) entre otros.

Otro elemento que podemos encontrar formando parte de la cubierta de la fosa de inhumación en la maqbara de Marroquíes son los ladrillos cocidos al sol, adobes (libn) que en este caso se disponen enmarcando la fosa de inhumación. ¿Se trata de un adorno para embellecer la tumba? o ¿tiene una función de sujeción de una cubierta propiamente dicha que estaría formada por un material perecedero como la madera o el cañizo? Nosotros nos inclinamos por la segunda opción, primero se colocaría la tabla o un entramado vegetal y posteriormente, para que no quedara ningún resquicio por el que entrara la tierra en la fosa de inhumación, ésta se bordearía con ladrillos de adobe, sellando las fisuras laterales. Por otro lado, la disposición de los adobes, el mismo tamaño, alineados, en algunos casos marcando la cabecera, indica que se ha realizado con máximo cuidado, intentando buscar cierta armonía y belleza. Aunque son escasos los enterramientos que utilizan este tipo de cubierta, pues sólo aparecen ocho tumbas $(1,5 \%)$ resulta significativo, ya que todas se corresponden con el tipo de prefosa y fosa central de inhumación o $\check{s} a q q$. Asimismo, seis de ellas tienen una orientación de Tendencia Sur, cuadrante $S E$, mientras que dos, las situadas más al norte tienen una orientación de Tendencia de compromiso. Por edades, seis pertenecen a infantiles, mientras que dos son adultos. Se concentran en el centro oeste de la necrópolis, a excepción de un caso, también de un difunto infantil, localizado en el extremo sur del cementerio y con unas características peculiares, donde los adobes que rodean la fosa de inhumación tienen claramente marcada la cabecera, como en otros casos, pero ésta se sitúa donde deberían estar los pies (al este). Al no tener cadáver, ya que se trataría por las medidas que tiene la fosa de inhumación de un individuo infantil, menor de un año, no podemos asegurar que se trata de una tumba invertida, pudiendo tratarse, simplemente, de una manera de colocar los adobes que nos llevan a confusión. En cuanto a los paralelos de este tipo de cubierta documentados en al-Andalus, se han excavado en la maqbara de Lorca (Chávet Lozoya, 2015), pero también y así lo recogen Tendero Porras et al. (2007) en Valladolid, en Santa Eulalia en Murcia, en la maqbara de Calatrava la Vieja en Ciudad Real, en la Rinconeda de Olivares en Jumilla, en la necrópolis de Derrocat en Petret, Alicante, etc.

La presencia de piedras, o bien como cubierta o bien como señalización, como hemos visto anteriormente, aparece con frecuencia, aunque con varias variantes:

- Una o varias piedras colocadas en los pies, 16 tumbas que suponen casi un 2,5\%.

- Losa de piedra en los laterales: se constata en cinco sepulturas. Hay que recordar que estos tipos de cubierta, con toda probabilidad, estarían sobre otro elemento de material perecedero que sería realmente la cubierta.

- Losas de piedra abarcando toda o gran parte de la fosa de inhumación: se detecta en 13 sepulturas.

- Piedras en la cabecera, este tipo de cubierta es escasa, sólo hay dos casos y en ambos habría que matizar algunos aspectos. El caso de la T 59, se trata de piedras y adobes intercalados marcando la cabecera. Mientras que el segundo es una piedra de tamaño medio superpuesta a un elemento cerámico. Los paralelos de estas son muy abundantes, documentándose por toda la península, tanto en época islámica como anteriores.

Según las creencias islámicas «la utilización de ladrillos y cal para revestir la tumba, puesto que ambos son materiales expuestos al fuego, podrían 
desecar no solo el cuerpo, sino también el alma de la persona fallecida» (Abad Castro y González Cavero, 2008: 7). No obstante, este tipo de cubierta, especialmente una cubierta con tejas, es una de las más documentadas en las necrópolis de al-Andalus, con una cronología muy amplia, abarcando todo el período islámico (Casal García, 2001: 297).

En esta necrópolis sólo contamos con 26 enterramientos con cubierta de tejas.

\subsection{POSICIÓN DEL CADÁVER Y MOVIMIENTOS POSTDEPO- SICIONALES}

A la hora de colocar el cadáver en la tumba, algunos autores defienden (Ruiz, 2014) que ésta se disponía de una u otra forma dependiendo de la corriente que predominaba en este momento. La tradicionalista se caracterizaba por colocar al individuo en decúbito supino y con el rostro girado hacia la posición canónica y la corriente maliki, que se consolida a partir del siglo $\mathrm{X}$, se identifica por la colocación decúbito lateral derecho. No obstante, en la Risāla (comienza a tener vigencia en al-Andalus a partir del siglo X, lo que quiere decir que también a partir de este momento podríamos encontrar enterramientos en decúbito supino) se recoge que eran válidas las dos posturas, «bien sobre su lado derecho orientado al este, bien tumbado sobre la espalda con el rostro orientado al este» (Chávet Lozoya, 2015: 128). En nuestro caso no creemos que se pueda hacer una distinción de este ritual por su posición, porque los enterramientos documentados en posición decúbito supino son muy escasos y se encuentran en puntos distantes, sin relación entre ellos.

En la maqbara de la ZAMB, la gran mayoría de los cuerpos documentados están en posición decúbito lateral derecho y sólo seis enterramientos presentan la posición decúbito supino. Pero de éstos, tres se sitúan fuera del área de la necrópolis, y no se pudo identificar la fosa de inhumación, que se sitúa en el patio de una vivienda, que será abandonada en época almohade. El resto de los enterramientos, ¿podrían pertenecer al ritual tradicionalista? Dos se sitúan en el extremo sur de la necrópolis, junto al límite del camino, en cambio, la tercera, se localiza en el centro del cementerio, alejado del camino.

En cualquier caso, las fosas de inhumación son muy estrechas para evitar que el cuerpo, una vez perdida la conexión anatómica, se desplazara. Para ayudar a que esto no pasara, se ponían pequeños calzos compuestos de piedras, cascotes de cerámica, etc (León Muñoz, 2008-2009). En nuestro caso, apenas se han documentado estos elementos, pero se ha podido comprobar que la cabeza se encuentra elevada por medio de la colocación simplemente de tierra. No creemos que ésta se pusiera directamente sobre un «puñado» de tierra, más bien, se pondría una tabla de madera o similar que sería calzada por tierra y alguna piedra de pequeño tamaño.

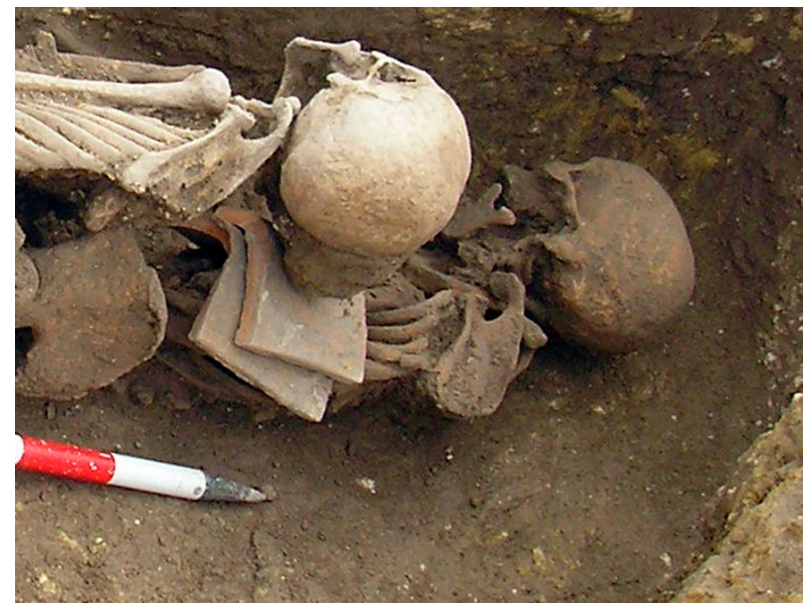

Figura 14: T 221. Corte 74. Solar de la Futura Ciudad de la Justicia.

El caso más significativo documentado en el que aparece cerámica para elevar la cabeza del difunto, lo tenemos en uno de los dos enterramientos múltiples o colectivos (T 221) (Fig. 14), en el que en una misma fosa se entierran dos individuos, un cuerpo directamente sobre otro. El cuerpo que se encuentra encima sólo lo separan del primer enterramiento dos trozos de tinaja fragmentada colocada sobre el tórax del primer individuo y algo de tierra o adobe colocado sobre las tejas para elevar más el cráneo del segundo enterramiento.

Por último, otra posición del cadáver que se ha documentado ha sido decúbito casi prono, con diez casos. Esta posición está relacionada directamente con el rigor mortis y procesos postdeposicionales derivados de la descomposición y movimiento de la cubierta de la fosa de inhumación. En ningún caso podemos considerarla como una postura intencionada.

\section{6. Elementos de AJuAr o AdORNo PERSONAL.}

Los elementos de ajuar documentados en esta maqbara son muy escasos. La mayoría del material recuperado pertenece fundamentalmente a fragmentos de cerámica prehistórica, que formaban parte del relleno de tierra con el que se cubría dichas tumbas. Por lo que respecta al incluido ex professo en la tumba como elemento de ajuar o adorno personal, sólo podemos destacar la presencia de dos elementos: un alfiler de metal elaborado en cobre, de cabeza bífida y sección rectangular (Barba et al, 2010) que se documentó en el interior de la fosa de inhumación de una tumba. Este enterramiento compuesto de una fosa simple pertenecía a un niño de corta edad, ya que la fosa de inhumación era de 0,98 $\mathrm{m}$; los restos óseos no han llegado hasta nosotros, sin embargo, sí ha quedado este pequeño alfiler (mide 46,71 $\mathrm{mm}$ ). Tanto la tumba como el alfiler se han datado en el siglo X. Estos elementos son relativamente comunes y servían para sujetar el sudario. Y una lamina de oro (Barba Colmenero y Navarro Pérez, 2010) localizada en el corte 16 del solar de la Ciudad de la Justicia que, 
como en el caso anterior, aparece en una tumba infantil. Hasta el momento, no hemos encontrado paralelos de tumbas en las que se haya documentado una lámina de oro en su interior, además no conocemos su funcionalidad, ni su aspecto original. Actualmente presenta una forma trapezoidal con unas dimensiones de $18 \times 6 \mathrm{~mm}$ (Barba Colmenero y Navarro Pérez, 2010).

Hay que señalar la presencia, fuera de las tumbas, en el espacio correspondiente a las calles interiores del cementerio, de candiles, que pueden estar asociados a la tradición de oraciones nocturnas en las siete noches posteriores al entierro (Tomasseti et al., 2005).

\section{CONCLUSIONES. FASES DE USO DE LA MA- QBARA}

Fundación de la maqbara. Periodo Emiral. El establecimiento de la maqbara se encuentra íntimamente unido al tema de la propiedad del terreno donde se ubica. En el caso de la fundación de la maqbara del camino de Bayyāsa se realiza sobre un territorio que no estaba ocupado anteriormente, no se han excavado niveles ni estructuras, sólo un espacio de huerta que se superpone a la ocupación prehistórica. Tampoco se documentan estratos posteriores al abandono de la misma. Esto es importante, ya que no debe de haber edificios contiguos a los cementerios, los alfaquíes argumentan que las tumbas se pueden convertir en lugar de paso, algo que no era recomendable (Carballeira Debasa, 2002). El procedimiento habitual para la instauración de un cementerio se hacía a través de un habiz, donación de un terreno privado en favor de la comunidad, adquiriendo estos lugares un carácter inalterable (León Muñoz y Casal García, 2010).

Sobre la fundación de la maqbara del camino de Bayyāsa caben varias hipótesis:

1.- Que la maqbara sea producto de un legado piadoso por un personaje poderoso o, al menos, con el suficiente patrimonio para donar el terreno, siendo en un primer momento un cementerio familiar. Tras la excavación realizada en el solar de la futura Ciudad de la Justicia, se planteó que el inicio de la necrópolis estaba en íntima relación con la vivienda 1, de época emiral, y el «mausoleo» o qubba que se encuentra frente a la misma, siendo éste el inicio del cementerio $\mathrm{y}$, por tanto, el culpable de su fundación. En algunos casos la presencia de una qubba es la causante de la existencia de una necrópolis, llegando incluso a tomar el nombre del personaje enterrado (Casal García, 2003). Según algunos autores (León Muñoz y Casal García, 2010) es bastante habitual que individuos considerados sabios se enterraran en la puerta de su casa, incluso en zonas urbanas. Esta hipótesis vendría respaldada por la presencia de un grupo de enterramientos situados frente a la vivienda 1 y que por localización, orientación y tipología de tumbas (Tendencia Este y mayoritariamente tumbas tipo lahd) presenta importantes diferencias respecto a los enterramientos de su entorno.

Al mismo tiempo se entierran otros individuos tal vez configurando otros grupos familiares. De esta manera, los primeros enterramientos y, por tanto, fundadores de la necrópolis (finales del siglo VIII, principios del IX) estarían formados por tres pequeños grupos en el extremo norte de la necrópolis, que comparten una serie de características además de su ubicación (frente a la vivienda 1 y junto al camino al norte de la maqbara), ya que todos conservan una misma orientación, Tendencia Este, y en segundo lugar, todos se entierran en tumbas tipo lahd.

No obstante, ahora sabemos que la construcción de esta estructura (qubba) que agrupa los dos enterramientos, se realiza cuando se entierra al segundo individuo. Por tanto, este elemento se construye en una segunda fase cuando el cementerio ya estaba fundado. Ello no invalida que éste se hubiera iniciado por un grupo familiar al que pertenecía el primer personaje y lo hiciera junto a la puerta de su casa o, al menos, en los aledaños de ésta. En un segundo momento, se produce el enterramiento de un personaje en torno al cual se edifica la $q u b b a$. Esta tumba se alinea con las anteriores tomando su orientación, pero su fosa, a diferencia de los primeros, se construye tipo $\check{s} a q q$, algo que se repite en el resto de grupos. Por tanto, la primera fase se caracteriza por el enterramiento de tres grupos no muy alejados unos de otros, todos junto al camino, utilizándose dos tipos de enterramiento, que se repiten en todos los grupos. Somos conscientes de que son fundamentalmente criterios tipológicos, de situación, de orientación y de organización de las sepulturas los que sustentan nuestra hipótesis sobre el nacimiento de esta maqbara, pero son tan coincidentes, que resulta difícil aceptar que sea una mera casualidad, y que dichas tumbas no tengan relación cronológica entre sí.

El tema sobre la propiedad del terreno es otro asunto, no acaba de encajar en esta hipótesis, ya que no comprendemos cómo, si esta pertenecían a un grupo (propietarios de la vivienda 1), el muro que rodeaba la casa no englobaba toda la finca. Además se encuentran separados por un camino que dudamos, dada la parcelación existente en estos momentos, que partiera la propiedad. Esto nos lleva a plantear la segunda hipótesis.

2.- La segunda opción es que existiera una «promoción planificada» por las autoridades islámicas, ya que por lo general la fundación de las maqabir eran responsabilidad de éstas, del qā 2010). La gran mayoría de las fundaciones tenían un carácter político, esto no sólo se produce en el interior de las ciudades, sino que se trasladó también a la zona extramuros, creando en torno a almunias, arrabales y grandes propiedades agrícolas, espacios plenamente islamizados (León Muñoz y Casal García, 2010).

Este proceso se inicia en Marroquíes Bajos en fechas tempranas, aunque continúa después del año 
756 con la proclamación del emirato independiente por Abd al-Raḥmān y el proyecto impulsado por el Estado Omeya cuya prioridad era la islamización de la sociedad (Acien Almansa y Vallejo Triano, 1998; León Muñoz y Casal García, 2010). Pudo ser en este momento cuando se produzca una nueva división del espacio que ocupa la actual Zona Arqueológica y probablemente de todo el territorio que hasta ese momento estaba en manos de la aristocracia y la iglesia. Dentro de la nueva distribución del territorio orquestada desde el Estado, no es difícil pensar que con la planificación se reservara un área para la maqbara, en la que se enterrarían aquellas familias musulmanas que vivían en las casas agrícolas del entorno, produciendo así una cohesión entre la zona de hábitat, de producción agrícola y funeraria. Siguiendo esta segunda hipótesis, los primeros enterramientos se agrupan junto al margen del camino, formando pequeños conjuntos sin que aparentemente haya una conexión entre ellos. Probablemente, como ya indicábamos en el apartado de organización interna de la necrópolis, éstos están unidos por lazos de parentesco o similares que se corresponderían con las grandes propiedades que se han documentado en este espacio de Marroquíes Bajos. Por tanto, la distribución de los enterramientos se sucede del mismo modo que en la primera hipótesis. La diferencia entre ambas teorías no está tanto en la distribución de las tumbas en el interior del cementerio, como en las causas que la motivaron.

Sea cual fuera la casuística de su fundación, a finales del siglo IX el cementerio se densifica, aunque extendiéndose hacia el sur. Probablemente se puede poner en relación con la consolidación de las grandes casas agrícolas del entorno, en un período de transformación que coincide con el nombramiento de $\hat{Y}$ ayyān como capital de la cora, en tiempos de ${ }^{\mathrm{c}} \mathrm{Abd}$ al-Rahmān II, algo que se verá plasmado en el crecimiento de la población y, por tanto, en la densidad del número de individuos enterrados. Por otra parte el tipo de tumbas se diversifica.

Esta diferenciación ¿nos está indicando la presencia de dos grupos? Por un lado, los fundadores de la necrópolis, probablemente foráneos, árabes o beréberes que habían recibido el terreno colindante a la necrópolis como recompensa a su apoyo a los omeyas, y por otro, arrendatarios de propiedades cercanas, campesinos hispano-romanos que, en un proceso, parece que no demasiado lento, se han ido convirtiendo al Islam, por lo que se entierran ya en una maqbara, con los ritos claramente musulmanes aunque con un tipo de fosas que «pueden identificarse como las estructuras creadas por una comunidad hispanovisigoda que ha decidido convertirse al islam, y que ha empezado a islamizarse adaptando sus antiguas costumbres de enterramiento al ritual islámico» (Serrano Peña y Castillo Armenteros, 2000: 100), y con una orientación que sustancialmente mantiene la de las sepulturas cristianas.

A finales del siglo IX y coincidiendo con un momento de conflicto provocado por las revueltas muladíes, se asiste a un abandono momentáneo de ésta, algo que también se producía en el oratorio y que se verá claramente documentado en la vivienda 1 de la Ciudad de la Justicia. Este proceso, que es difícil de apreciar en una necrópolis, aún más teniendo en cuenta su posterior continuidad, se ha podido detectar por varios motivos: en primer lugar por el hecho de no considerarla como un espacio aislado sin relación con el entorno; en segundo lugar, por el cambio que se produce en la orientación de las tumbas y su nueva distribución espacial dentro de la necrópolis. Esto nos ha llevado a plantearnos si, además de estos cambios, se podía reconocer ese momento de conflicto bélico o episodio de inestabilidad militar.

Tenemos en la maqbara algunos enterramientos (al menos seis) con claros signos de muerte violenta. De estos, cuatro tumbas se encuentran en la zona sur junto al camino, compartiendo características (localización y orientación Tendencia Sur, cuadrante SE), con los enterramientos datados para el momento final del siglo IX, principios del X. Los otros dos se sitúan junto al grupo enterrado al norte de la necrópolis inmediato a la $q u b b a$, también datados en esta primera fase.

Las tumbas aparecidas, fuera de la necrópolis, en lo que luego fue el patio de la mezquita, podrían encuadrase en estos momentos. Es verosímil pensar que habían muerto dentro de estos enfrentamientos y enterrados junto al oratorio islámico, que en ese momento debía de estar recientemente abandonado. Estas tumbas con orientación cristiana debían de pertenecer a individuos de la comunidad que profesaban esta fe y que aún existía en la zona. Una vez que la situación se tranquiliza, después de casi cuatro décadas de conflictos, en pleno proceso de adecuación y recuperación de la mezquita, dichos individuos serán sepultados juntos con la orientación característica del rito islámico y perpendicular a la quibla de la mezquita.

Segundo Período. El califato Omeya. Sea de una manera o de otra, el espacio se abandona, por la inestabilidad provocada por los conflictos que sacuden al-Andalus desde finales del siglo IX. Recuperado el control del Estado, se reorganiza el territorio, incluyendo la necrópolis. En este momento la maqbara se establece en el mismo espacio que la anterior pero, si en la fase de fundación no encontrábamos en la disposición de las tumbas indicadores de un diseño establecido, aunque sí había indicios de alineamientos más o menos paralelos, ahora se reorganiza el espacio interno, siguiendo un proyecto ordenado. Al menos así lo sugieren los restos arqueológicos documentados ya que las tumbas siguen una alineación bien marcada, perpendicular al camino y se constituyen pequeños pasillos entre ellas.

Hemos dividido los enterramientos de este período en dos fases, un primer momento donde aún se está reorganizando el espacio (Califal 1) y un segundo (Califal 2) donde ya está plenamente consolidado. Esta partición se ha realizado en función de la orientación 


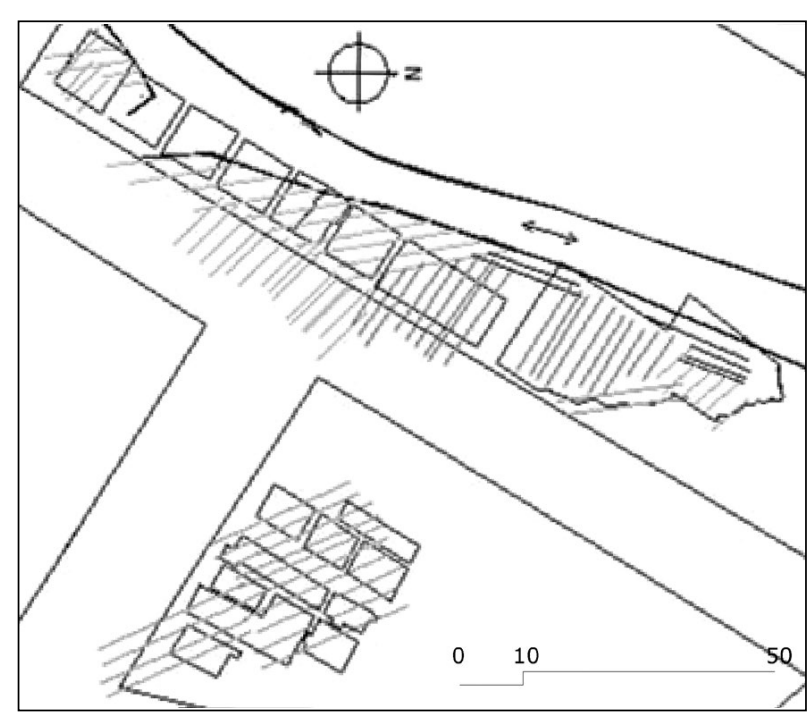

Figura 15: Distribución de las tumbas por calles.

que presentan las fosas de inhumación, que mayoritariamente muestran una alineación con Tendencia Cordobesa con un total de 203 enterramientos, seguidas de las que se construyen con una orientación con Tendencia de Compromiso, en torno a las 285 fosas. Tanto unas como otras ocupan un mismo espacio dentro de la necrópolis y en la mayoría de los casos respetan la separación entre tumbas, por lo que se ha de pensar que todas ellas estén funcionando a la vez. Los enterramientos construidos en época Califal se sitúan junto a las tumbas de época emiral, localizándose al este de las mismas sin invadir, en ningún momento, el espacio que ocupaban. Por tanto tenemos que pensar que a pesar de que no se conserven señalizaciones, en la mayoría de los casos debían de existir, siendo totalmente reconocibles. La alta densidad de enterramientos hace que $l a$ maqbara se vaya desplazando hacia el este, alejándose de los límites del camino, hasta $90 \mathrm{~m}$.

Espacialmente se puede apreciar una mayor concentración de tumbas con Tendencia de Compromiso hacia el noroeste, mientras que las de Tendencia Cordobesa se concentran más hacia el sur y el este, colocándose junto a las tumbas documentadas para época Emiral que se alineaban en torno al camino. Por tanto, dependiendo del período en el que nos encontremos, la maqbara se distribuirá con calles que presentan diferente alineación, pero que guardan, grosso modo, una misma anchura como se puede ver en la figura 15.

Sobre el tipo de fosa, como en el caso anterior, se documentan los tres ejemplos identificados en esta necrópolis. La más representada es la fosa simple, con 241 enterramientos algo que como venimos viendo se repite en todas las fases. El tipo de fosa $̌$ aqq se sigue manteniendo en este momento con un número importante, 113 tumbas, aunque en tanto por ciento supone un descenso respecto a las que había en época Emiral, ya que ahora tenemos un $29 \%$, mientras que en la fase anterior suponían un 38\%. En cuanto a las tumbas con fosa de tipo lahd, la diferencia entre las Tendencias
Cordobesa y de Compromiso se hace más evidente, tan solo nueve de la primera y 37 de la segunda. Pero como vemos, este tipo también está representado en esta fase.

En cuanto a las cubiertas que han llegado hasta nosotros, se encuentran representados todos los tipos, con mayor número las fosas de inhumación con cubiertas de losas de piedra y de teja. En época emiral la cubierta que más destacaba también era la losa de piedra, mientras que la teja solo la encontramos en una tumba. Sin embargo, había un buen número de tumbas con adobe.

Tercer Período. Almorávides y Almohades. En taifas, el asentamiento parece estar prácticamente abandonado, al menos a nivel de hábitat. Es muy probable que los campos se siguieran cultivando, al fin y al cabo, sería la huerta de la ciudad y de ella dependería. Pero el nuevo período de inestabilidad tiene como consecuencia que la gente viviera intramuros.

Una vez que la ciudad retoma la paz, la zona de Marroquíes vuelve a ocuparse y con ella su necrópolis. Se documentan un total de 128 enterramientos, todos ellos conformados por fosas simples y una orientación de Tendencia de Compromiso. Se encuentra dispersa por casi toda la necrópolis aunque alejada significativamente del camino lateral, con una concentración muy importante en el extremo este del cementerio. Además hay que recordar que es en este momento cuando se excavan enterramientos fuera del área de la maqbara propiamente dicha, aunque cercanos.

Por último vamos a ver hasta qué punto la cantidad de enterramientos puede permitir aproximarnos al número de habitantes que habría en la zona en cada una de las fases. Para ello tenemos que advertir, en primer lugar, que se trata de cifras aproximadas, ya que hay zonas que no se han excavado. En época emiral, calculado desde que ${ }^{c} \mathrm{Abd}$ al-Rahmān I se hiciera con el control de al-Andalus y repartiera el territorio (año 760 aproximadamente), según la hipótesis ya apuntada hasta el inicio de la crisis del emirato en Jaén, que situamos en 890 (Salvatierra, 2001) son unos 130 años, periodo de tiempo que corresponde, redondeando, a entre 3,5 y 4,5 generaciones. Se han documentado 157 fosas pertenecientes a un número similar de individuos $\mathrm{y}$, por tanto, a unas 35 a 45 personas en cada generación que profesan la religión islámica. Sabemos que estas cifras no son reales, ya que no tienen en cuenta la progresión que se produce con el aumento de conversiones, pero nos da una idea del número de habitantes musulmanes en este momento en la zona.

Durante el Califato Omeya, se produce un aumento considerable de población, ya que desde el restablecimiento del poder en la zona por 'Abd al-Raḥmān III hacia 915, hasta la destrucción de Marroquíes en 1014, son unos 100 años, es decir para 3 a 3,5 generaciones se entierran un total de 360 individuos, lo que vendría a corresponder con 102 a 120 individuos por generación. En estos momentos la población cristiana posiblemente había descendido ya de forma importante. 
Por último, aunque en la bibliografía se suele hablar exclusivamente de periodo almohade, es probable que la nueva ocupación de Marroquíes Bajos se iniciase ya en época almorávide. En conjunto el periodo abarcaría desde 1095 a 1225. La primera fecha corresponde a la consolidación de los almorávides en al-Andalus -la toma de Jaén fue en 1091- momento a partir del cual quizá empezó a recuperarse el asentamiento de Marroquíes, y la segunda al primer cerco de Jaén por Fernando III, cuando este debió ser abandonado definitivamente. Son otros 130 años de ocupación aproximadamente, en los que se registra el menor número de enterramientos, con 128 tumbas, para 3,5 a 4,5 generaciones, lo que supondría entre 28 y 36 individuos por generación, recuperando en el mejor de los casos las proporciones del emirato.

Estas cifras tienen interés porque apuntan que ésta no era una necrópolis vinculada prioritariamente a la ciudad, sino probablemente a los habitantes de las huertas, despejando otra de las dudas que en ocasiones se han planteado respecto a la función de la misma.

\section{REFERENCIAS}

Abad Castro, C. y González Cavero, I. (2008). Los enterramientos reales de Córdoba y el particularismo religioso andalusí en el contexto de la arquitectura funeraria islámica hasta el siglo X. Anuario del Departamento de Historia y Teoría del Arte, 20, 7-18.

Acién Almansa, M. y Vallejo Triano, A. (1998). Urbanismo y Estado islámico: de Corduba a Qurțuba-Madināt al-Zahrā. En P. Cressier y M. García-Arenal (Eds.). Genèse de la ville islamique en al-Andalus et au Magreb Occidental (pp. 107136). Madrid: Casa de Velázquez.

Aguirre Sádaba, J. y Jiménez Mata, M. ${ }^{a}$ C. (1979). Introducción al Jaén Islámico (Estudio Geográfico Histórico). Jaén: Instituto de Estudios Giennenses.

Alba Calzado, M. (2005). Dos áreas funerarias superpuestas, paganas e islámicas, en la zona sur de Mérida. Mérida. Excavaciones Arqueológicas 2002, 8, 338-339.

Barba Colmenero, V., Alcalá Lirio, F., Arias de Haro, F., Navarro Pérez, M. y Herranz Sánchez, A., (2004). Nuevos datos para el estudio del sistema de fortificación medieval de la ciudad de Jaén. Intervención Arqueológica en la Puerta de Martos. Arqueología y Territorio Medieval, 11(2), 77-91.

Barba Colmenero, V. y Navarro Pérez, M. (2010). La excavación arqueológica en la Ciudad de la Justicia de Jaén. En VV. AA. Ciudad de la Justicia de Jaén. Excavaciones arqueológicas (pp. 70-89). Sevilla: Consejería de Justicia y Administración Pública. Junta de Andalucía.

Bianquis, Th. (1994). Sépultures islamiques. En Topoi, volume 4/1 (pp 209-218), ). Recuperado de: https://www. persee.fr/doc/topoi_1161-9473_1994_num_4_1_1501

Calvo Capilla, S. (2004). Las Mezquitas de pequeñas ciudades y núcleos rurales de al-Andalus. Revista de Ciencias de las Religiones Anejos, X, 39-63.
Calvo Capilla, S. (2014). Las Mezquitas de al-Andalus. Almería: Fundación Ibn Tufayl de Estudios Árabes.

Carballeira Debasa, A. M. a (2002). Legados pios y fundaciones familiares en al-Andalus (siglos IV/X-VI/XII). Colección Estudios Árabes e Islámicos, Monografías 2. Madrid: Consejo Superior de Investigaciones Científicas.

Casal García, M ${ }^{\mathrm{a}}$ T. (2001). Los cementerios islámicos de Qurțuba. Anales de Arqueología Cordobesa, 12, 283-313. Recuperado de: https://www.persee.fr/doc/ topoi_1161-9473_1994_num_4_1_1501

Casal García, M. ${ }^{\mathrm{a}}$ T. (2003). Los cementerios musulmanes de Qurțba. Córdoba: Servicio de Publicaciones de la Universidad de Córdoba-Delegación de Cultura de la Diputación de Córdoba.

Casal García, M. a T. (2005). El ritual funerario islámico en Qurțuba, capital de al-Andalus. En F. J. Barca Durán y J. Jiménez Ávila (Eds). Enfermedad, muerte y cultura en las sociedades del pasado. Importancia de la contextualización en los estudios paleopatológicos. Importancia de la contextualización en estudios paleopatológicos, vol. I (pp. 301-316). Cáceres: Fundación Academia Europea de Yuste.

Castillo Armenteros, J. C., Navarro Pérez, M. y Serrano Peña, J. L. (2011). La Maqbara de Marroquíes Bajos (Jaén) en torno al 711. En L. A. García Moreno y A. Vigil-Escalera (Coords.). 711. Arqueología e Historia entre dos mundos, vol. I. Zona Arqueológica, 15 (pp. 273-292). Alcalá de Henares: Museo Arqueológico Regional.

Castro López, M., Zafra de la Torre, N. y Hornos Mata, F. (2008). El lugar de Marroquíes Bajos (Jaén, España) Localización y ordenación interna. Era Arqueológica, 8, 148-157.

Chávet Lozoya, M. (2015). Los rituales de enterramiento islámicos en al-Andalus (ss. VIII-XVI): las tumbas tipo lahd. Arqueología de la Muerte en Madīnat Lürqa. (Tesis Doctoral). Universidad de Granada. Granada. Recuperado de: https://hera.ugr.es/tesisugr/26442401.pdf

Chávet Lozoya, M., Sánchez Gallego, R. y Padial Pérez, J. (2006). Ensayo de rituales de enterramiento islámicos en alAndalus. Anales de Prehistoria y Arqueología, 22, 149-161.

De Miguel Ibáñez, M. ${ }^{a}$ P. (2016). La maqbara de Pamplona (siglo VIII). Aportes de la osteoarqueología al conocimiento de la islamización en la Marca Superior. (Tesis Doctoral). Universidad de Alicante. Alicante. Recuperado de: http://hdl. handle.net/10045/54212

Dortez Cáceres, T. (2010). Urbanismo islámico en el sector central del Yanib al-Garbi. En D. Vaquerizo y J. F. Murillo. (Eds.). El Anfiteatro romano de Córdoba y su entorno urbano. Análisis arqueológico (ss. I-XIII d.C.). Monografías de Arqueología Cordobesa. 19. V. 2 (pp. 621-628). Córdoba: Convenio Universidad de Córdoba y Gerencia Municipal de Urbanismo del Ayuntamiento de Córdoba.

Eslava Galán, J. (1999). Castillos y Atalayas del Reino de Jaén. Jaén: Diario Ideal-La General.

Fernández Ordóñez, A., Barba Colmenero, V. y Nieto Ruiz, A. (2010). Informe de la Intervención Arqueológica en la 
Futura Sede de la Policía Local de Jaén. (Trabajo Inédito). Depositado en la Delegación Territorial de Cultura, Turismo y Deporte de la Junta de Andalucía en Jaén.

Fierro Bello, M. ${ }^{\mathrm{a}}$ I. (2000). El espacio de los muertos. Fetuas andalusíes sobre tumbas y cementerios. En P. Cressier, M. ${ }^{\mathrm{a}}$ I. Fierro y J.-P. van Staëvel (Eds.). L'urbanisme dans l'Occident médiéval au Moyen Age: aspects juridiques (pp. 153-189). Madrid: Casa de Velázquez-CSIC.

Gutiérrez González, F. J., Laliena Corbera, C. y Pina Pardos, M. (2016). La maqbara medieval de Tauste. Primeras investigaciones. En J. I. Lorenzo Lizalde y J. M. ${ }^{\text {a }}$ Rodanés Vicente (Eds). Actas I Congreso Arqueología, Patrimonio, Aragonés CAPA. 24 y 25 de noviembre de 2005. Sesión 3. Arqueología Medieval (pp. 433-442). Zaragoza: Colegio Oficial de Doctores y Licenciados en Filosofía y Letras y en Ciencias de Aragón.

Hornos Mata, F., Castro López, M. y Zafra de la Torre, N. (1998). La gestión de una zona arqueológica urbana. La experiencia de la investigación aplicada a Marroquíes Bajos. (Jaén). PH Boletin del Instituto Andaluz de Patrimonio Histórico, 22, 82-91.

Lázaro Damas, S. (1988). Desarrollo Histórico del casco urbano de Jaén hasta 1600. Jaén: Colegio de Aparejadores y Arquitectos técnicos.

León Muñoz, A. (2008-2009): ;Hombres! la promesa de Dios es verdadera... El mundo funerario islámico en Córdoba (siglos VIII-XIII). Arqueología Medieval, 4-5, 24-49. Recuperado de: http://www.raco.cat/index.php/ ArqueologiaMedieval/article/view/254544/341489

León Muñoz, A. y Casal García, M. ${ }^{\mathrm{a}}$ T. (2010). Los Cementerios de Madinat Qurțba. En D. Vaquerizo y J. F. Murillo (Eds.). El Anfiteatro Romano de Córdoba y su entorno urbano. Análisis Arqueológico (ss. I-XIII d.C.). Monografías de Arqueología Cordobesa. 19. V. 2 (pp. 651-684). Córdoba: Convenio Universidad de Córdoba y Gerencia Municipal de Urbanismo del Ayuntamiento de Córdoba.

López Quiroga, J. y Martínez Tejera, A. M. (2009). De corporibus defunctorum: lectura e interpretación históricoarqueológica del canon XVIII del primer concilio de Braga (a. 561) y su repercusión en la arquitectura hispana de la Antigüedad Tardía. En J. López Quiroga y A. M. Martínez Tejera (Eds.). Morir en el Mediterráneo Medieval. Actas del III Congreso Internacional de Arqueología, Arte e Historia de la Antigüedad Tardía y Alta Edad Media (pp. 153-182). Oxford: BAR Publishing.

López Seguí, E., Torregrosa Giménez, P., Quiles Muñoz, M. P., de Miguel Ibáñez, C. y Navarro Poveda, C. (2005). La necrópolis islámica de L'Alfossar (Novelda, Alicante). Recerques del Museu D'Alcoi, 14, 143-456.

Manzano Castillo, A. y Martínez Ocaña, J. L. (2009). Intervención Arqueológica en la Plaza de la Constitución. 1998. En Una imagen y mil piedras. La Arqueología de Jaén a través de la fotografía (pp. 75-76). Jaén: Diputación Provincial de Jaén. Cultura y Deportes.

Martínez Núñez, M ${ }^{a}$ A. (1994). La estela funeraria en el mundo andalusí. En C. de la Casa (Ed.). Actas del V Congreso Internacional de Estelas Funerarias (pp. 419-444). Soria.
Martínez Núñez, Ma A. (2001). Estelas funerarias de época califal aparecidas en Orihuela (Alicante). al-Qantara, 22(1), 45-76.

Martínez Núñez, M. ${ }^{\mathrm{a}}$ A. (2011). Epigrafía Funeraria en alAndalus (Siglos IX-XII). Mélanges de la Casa de Velázquez, 41(1), 181-209.

Martínez Ocaña, J. L. y Manzano Castillo, A. (2010). Intervención Arqueológica Preventiva en el Solar sito en C/ Conde 10 y 14 de Jaén. Anuario Arqueológico de Andalucía 2006, 2382-2404.

Martínez Rodríguez, A. y Montero Fenollós, J. (1996). La qubba islámica de la calle Cava ${ }^{\circ}{ }^{\circ} 11$, Lorca. Memorias de Arqueología, 11, 616-628.

Navarro Pérez, M. (2008). Memoria Preliminar de la Actuación Arqueológica Preventiva en el Solar de la Futura Ciudad de la Justicia. Jaén. (Trabajo Inédito). Depositado en la Delegación Territorial de Cultura, Turismo y Deporte de la Junta de Andalucía en Jaén.

Navarro Pérez, M. (2009). Intervención Arqueológica en el solar de la futura Ciudad de la Justicia. 2006-2007. En Una imagen y mil piedras. La Arqueología de Jaén a través de la fotografia (pp. 94-95). Jaén: Diputación Provincial de Jaén. Cultura y Deportes

Navarro Pérez, M. (2015). La transformación del paisaje. El caso de Marroquíes Bajos (Jaén) en época medieval. En Revista Arkeogazte/Arkeogazte Aldikaria. Anexo 1. Arqueologías Sociales, Arqueología de la Sociedad. Actas de las VII Jornadas de jóvenes en la investigación arqueológica (pp. 239-249). Vitoria: Arkeogazte.

Navarro Pérez, M. (2017). La ocupación del entorno de las ciudades islámicas en época omeya. Marroquíes Bajos. Jaén. (Tesis doctoral inédita). Universidad de Jaén. Jaén.

Olcina Domènech, M., Tendero Porras, E. y Guilabert Mars, A. P. (2008). La maqbara del Tossal de Manises (Alicante). Lucentum, XXVII, 213-228.

Peral Bejano, C. (1995). Excavación y estudio de los cementerios urbanos andalusíes. Estado de la cuestión. En M. Acien Almansa y $\mathrm{M}^{\mathrm{a}}$ de la P. Torres Palomo (Eds.). Estudios sobre cementerios islámicos andalusies (pp. 7-10). Málaga: Servicio de Publicaciones e Intercambio Científico de la Universidad de Málaga.

Pérez Martínez, M. ${ }^{a}$ C., López Marcos, A. y de Dios Pérez, M. A. (2004). Puerta del Aceituno. Arqueología y Territorio Medieval, 11(2), 93-124.

Portero Fernández, V., De la Torre, Y. y Ortiz, A. (2010). Intervención Arqueológica Preventiva en la Parcela DOC-3 del SUNP-1. ZAMB. Jaén. Anuario Arqueológico de Andalucía 2006, 3098-4017.

Raghib, Y. (1970). Les premiers monuments funeraires de 1'Islam. Annales islamologiques, 10, 21-36.

Raghib, Y. (1992). Structure de la tombre d'après le droit musulman. Arabica, 39, 393-403. 
Ribera y Tarragó, J. (1928). Ceremonias funebres de los árabes españoles. Esstudio liturgico. En Disertaciones y opúsculos, $t$. II (pp. 248-256). Madrid.

Ripoll López, G. (1989). Características generales del poblamiento y la arqueología funeraria visigoda en Hispania. Espacio, Tiempo y Forma. S. I. Prehistoria y Arqueología, $2,389-418$

Rius, M. (2000): La alquiba en al-Andalus y al-Magrib al-Aqșà. Anuari de Filología XXI. Barcelona: Universitat de Barcelona.

Ruíz Taboada, A. (2014). La muerte en el Madrid Andalusí. En Actas de las décimas Jornadas de Patrimonio Arqueológico en la Comunidad de Madrid (pp. 47-71). Madrid: Dirección General de Patrimonio Histórico.

Salvatierra Cuenca, V. (2001). La crisis en el emirato Omeya en el alto Guadalquivir: precisiones sobre la geografia de la rebelión muladí. Jaén: Servicio de Publicaciones. Universidad de Jaén.

Salvatierra Cuenca, V. (2009). El agua y la ciudad de Jaén en época Andalusí. Una Historia entrelazada.En XELB, 9. Actas do $6 .^{\circ}$ Encontro de Arqueología do Algarve. O Gharb no al-Andalus: sinteses e perspectivas de estudo. Homenagem a José Luis de Martos (Silves 23, 24 e 25 de Outibro 2008) (pp. 259-280). Silves: Camara Municipal de Silves.

Salvatierra Cuenca, V. (2010). Marroquíes Bajos en época Andalusí. En VV. AA. Ciudad de la Justicia de Jaén. Excavaciones arqueológicas (pp 58-67). Sevilla: Consejería de Justicia y Administración Pública. Junta de Andalucía.

Salvatierra Cuenca, V., Serrano Peña, J. L. y Pérez Martínez, M. ${ }^{\text {a C }}$ (1998). La formación de la ciudad en Al-Andalus. Elementos para una nueva propuesta. En P. Cressier y M. García-Arenal (Eds.). Genèse de la ville islamique en alAndalus et au Magreb oriental (pp. 185-206). Madrid: Casa de Velázquez.

Sánchez Vizcaíno, A., Bellón Ruiz, J. P. y Rueda Galán, C. (2005). Nuevos datos sobre la Zona Arqueológica de Marroquíes Bajos: el quinto foso. Trabajos de Prehistoria, 62(2), 151-164.

Serrano Peña J. L. y Castillo Armenteros J. C. (2000). Las necrópolis medievales de Marroquíes Bajos, (Jaén). Avance de las investigaciones arqueológicas. Arqueología y Territorio Medieval, 7, 93-120.
Serrano Peña, J. L., Barba Colmenero, V., Alcalá Lirio, F. y Cano Carrillo, J. (2002). La paleomorfología de Marroquíes Bajos. Primeras propuestas. Arqueología y Territorio Medieval, 9, 7-36.

Serrano Peña, J. L. y Molinos Molinos, M. (2011). La aristocracia ibérica ante la romanización. Ideología y espacios funerarios en Marroquíes Bajos (Jaén). Archivo Español de Arqueología, 84, 119-152.

Serrano Peña, J. L. y Salvatierra Cuenca, V. (2012). Evolución del urbanismo romano de Aurgis. En J. Beltrán Fortes y O. Rodríguez Gutiérrez (Eds.). Hispanae Urbes: Investigaciones Arqueológicas en ciudades históricas (pp. 584-605). Sevilla: Servicio de Publicaciones. Universidad de Sevilla.

Tendero Porras, E., Guilabert Mas, A. y Olcina Domènech, M. (2007). La maqbara del Tossal de Manises (Alicante). Tomo I. Estudio Arqueológico. Alicante: Museo Arqueológico de Alicante.

Tomassetti Guerra, J. M. (2005). El cementerio islámico de Fuerte de Santiago, Algeciras (Cádiz). Nuevas excavaciones y síntesis interpretativa. En Jornadas de arqueología del Campo de Gibraltar. Protección de patrimonio de Tarifa (pp. 103-104). Tarifa: Instituto de Estudios Campogilbratareños.

Tomassetti Guerra, J. M., Suárez Padilla, J., Bravo Jiménez, S., Jiménez-Camino, R. M. ${ }^{\text {a }, ~ y ~ N a v a r r o ~ L u e n g o, ~ I . ~(2006) . ~}$ El cementerio islámico de Fuerte de Santiago (Algeciras, Cádiz). Nuevas excavaciones y síntesis interpretativa. Almoraima, 33, 147-170.

Torres Balbás, L. (1957). Los cementerios hispanomusulmanes. Al-Andalus, XXII, 131-191.

Vigil-Escalera Guirado, A. (2015). La identidad de la comunidad local y las afiliaciones individuales en necrópolis de la Alta Edad Media (400-900 AD). En J. A. Quirós Castillo y S. Castellanos (Dirs.). Identidad y etnicidad en Hispania. Propuestas teóricas y cultura material en los siglos V-VIII (pp. 249-274). Bilbao: Servicio Editorial. Universidad del País Vasco.

Zafra de la Torre, N., Castro López, M. y Hornos Mata, F. (1999). Una macro-aldea en el origen del modo de vida campesino: Marroquíes Bajos (Jaén) c. 2500-2000 cal. ANE. Trabajos de Prehistoria, 56(1), 77-102. 